Supporting Information for

\title{
A Theoretical Study on the Geometry, Aromaticity, and Electronic Properties of Benzo[3,4]cyclobutathiophenes and Their Homologues
}

Shingo Hashimoto and Kazukuni Tahara*

Department of Applied Chemistry, School of Science and Technology, Meiji University, 1-1-1 Higashimita, Tama-ku, Kawasaki, Kanagawa 214-8571, Japan.

\section{Contents}

1. $R_{\mathrm{s}, j}$ and $R_{\mathrm{d}, j}$ values used for the HOMA analysis

2. Bond lengths of biphenylene, BCTs, their homologues, and $[N]$ phenylenes

3. HOMA and NICS values and AICD plots of benzene, thiophene, and cyclobutadiene

4. NICS- $X Y$ scans of biphenylene, $b \mathrm{BCT}$, and $c \mathrm{BCT}$

5. NICS $(0)_{\text {iso }}$ values of biphenylene, BCTs, their homologues, and $[N]$ phenylene except for the $b$ L-homologues

6. The non-planar geometry of $b \mathrm{~L} 1$

7. Diradical character $y_{\mathrm{d}}$ values for BCTs, biphenylene, and their homologues

8. Spin-density distributions of $b$ L-homologues

9. Calculated current strength using GIMIC method

10. AICD plots of BCTs, biphenylene, and the $b$-homologues

11. AICD plots and NICS $(0)_{\text {iso }}$ values for 1,3-cyclohexadiene

12. Discussion about the aromaticity of the $c$-homologues

13. Discussion about the aromaticity of $b c$-homologues

15. Molecular orbitals of biphenylene and BCTs and frontier orbital distributions of the BCT homologues

16. References

17. Cartesian coordinates for all optimized geometries 
1. $R_{\mathrm{s}, j}$ and $\boldsymbol{R}_{\mathrm{d}, j}$ values used for the HOMA analysis

Table S1. Summary of the $R_{\mathrm{s}}$ and $R_{\mathrm{d}}(\AA)$ values.

\begin{tabular}{ccc}
\hline$j$ (type of bond) & $R_{\mathrm{s}}{ }^{a}$ & $R_{\mathrm{d}}{ }^{a}$ \\
\hline carbon-carbon bond & $1.456^{b}$ & $1.338^{b}$ \\
carbon-sulfur bond & $1.823^{c}$ & $1.615^{d}$ \\
\hline
\end{tabular}

${ }^{a}$ Geometries were optimized at the B3LYP/6-311+G(d) level of theory. ${ }^{b}$ Calculated from the optimized structure of 1,3-butadiene $\left(\mathrm{CH}_{2}=\mathrm{CH}-\mathrm{CH}=\mathrm{CH}_{2}\right)$. ${ }^{c} \mathrm{Calculated}$ from the optimized structure of dimethyl sulfide $\left(\mathrm{H}_{3} \mathrm{C}-\mathrm{S}-\right.$ $\left.\mathrm{CH}_{3}\right) .{ }^{d}$ Calculated from the optimized structure of methanethial $\left(\mathrm{H}_{2} \mathrm{C}=\mathrm{S}\right)$.

2. Bond lengths of biphenylene, BCTs, their homologues, and [N]phenylenes

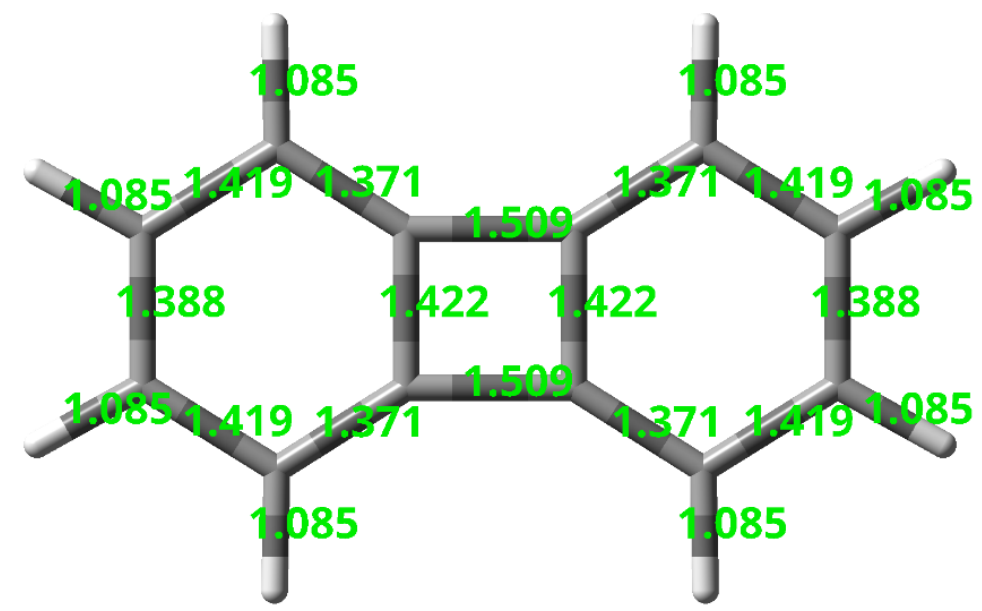

biphenylene

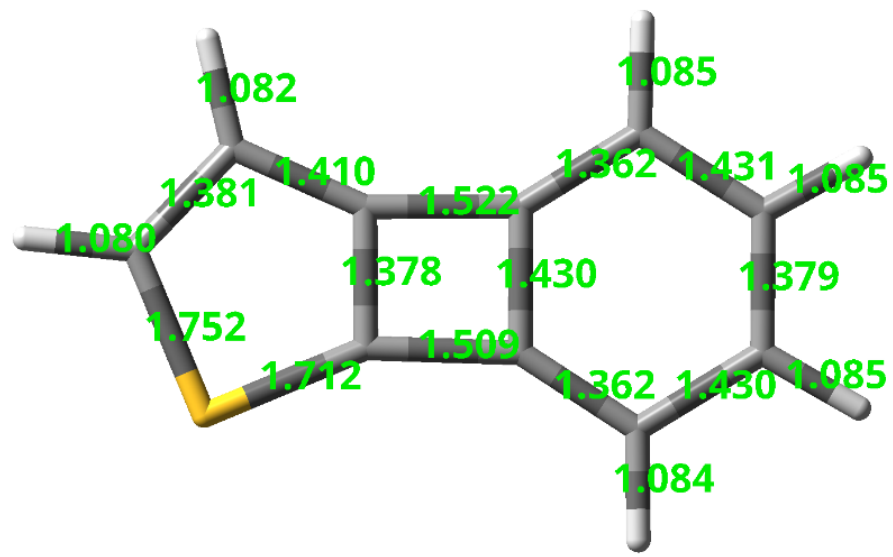

bBCT

Figure S1. Bond lengths of biphenylene, BCTs, their homologues, and $[N]$ phenylenes $(\AA)$. 


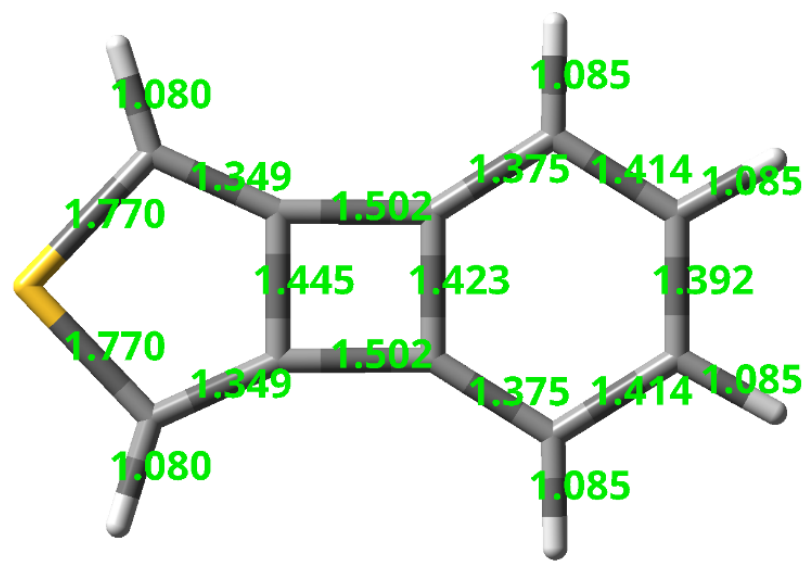

$c B C T$

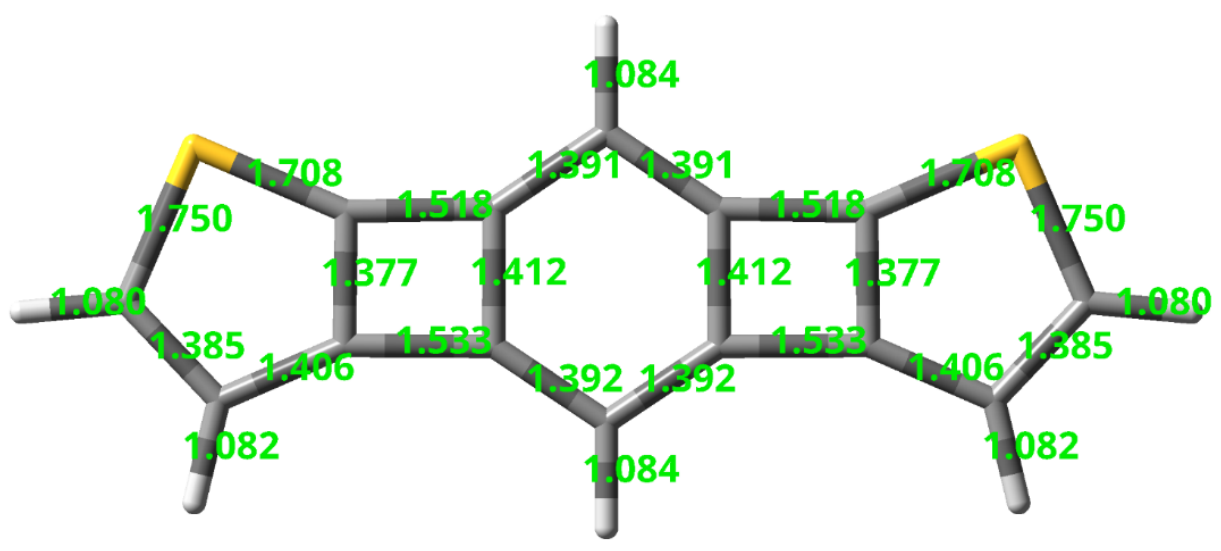

bL1

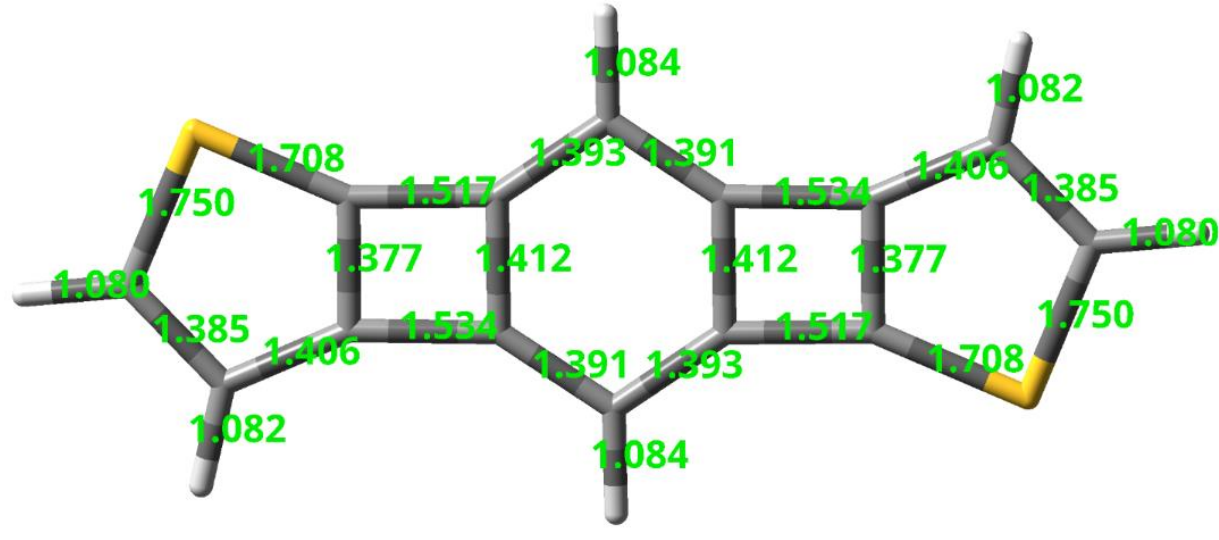

bL2

Figure S1 (Continued). Bond lengths of biphenylene, BCTs, their homologues, and $[N]$ phenylenes $(\AA)$. 


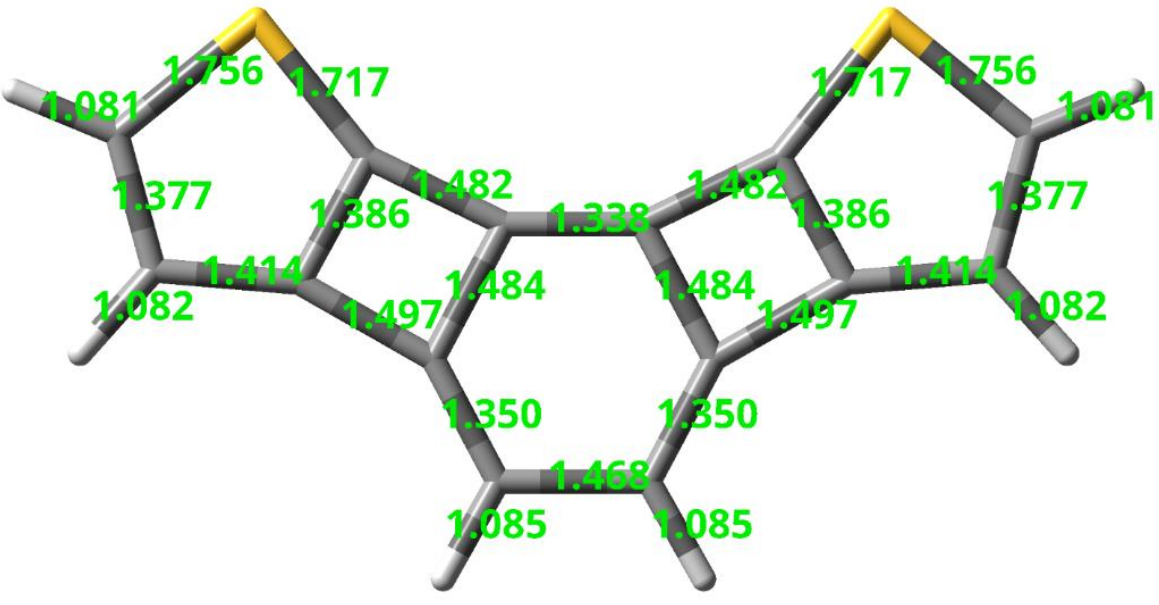

bA1

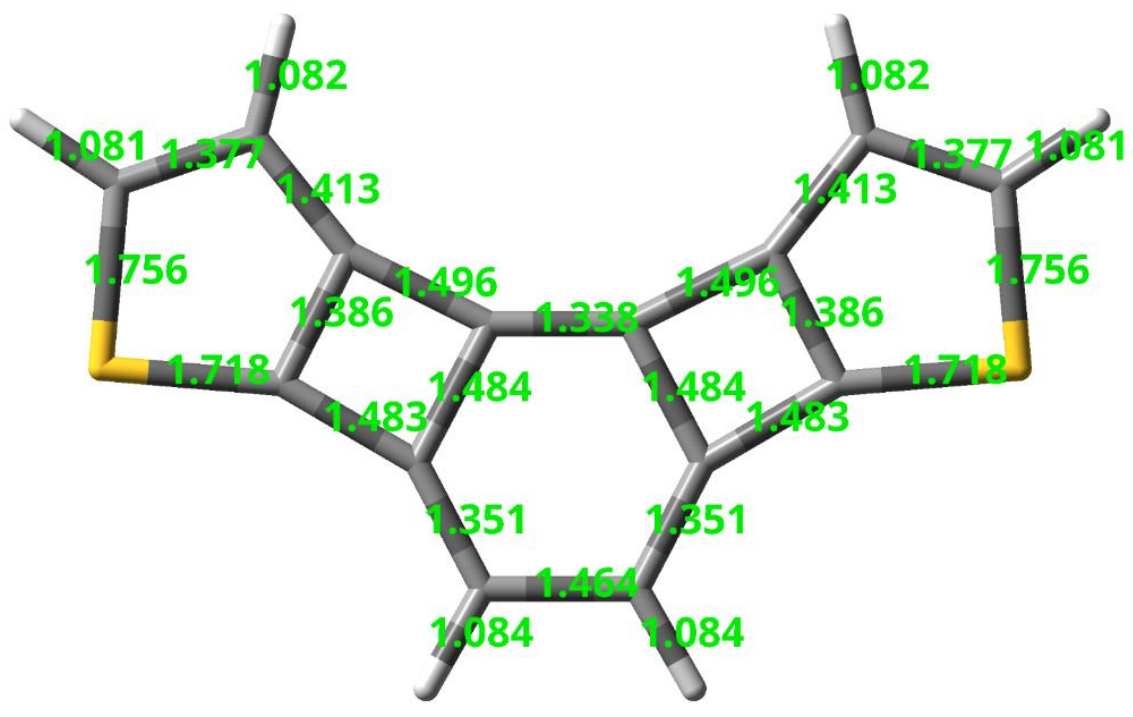

bA2

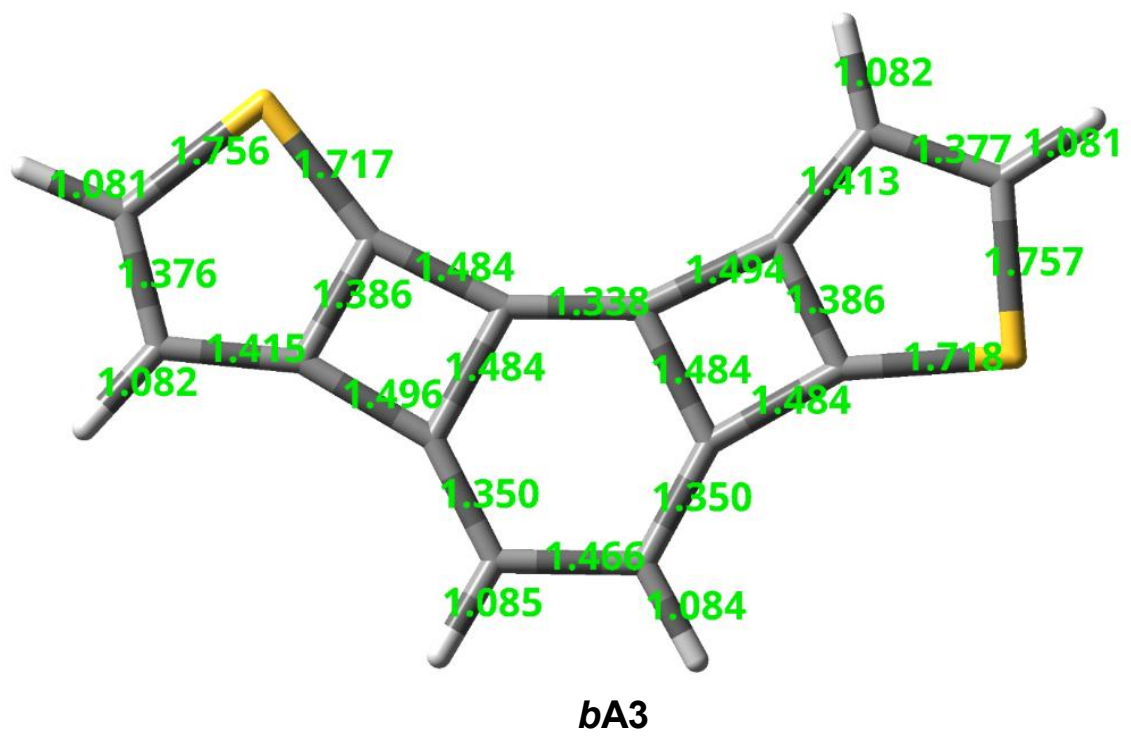

Figure S1 (Continued). Bond lengths of biphenylene, BCTs, their homologues, and $[N]$ phenylenes $(\AA)$. 


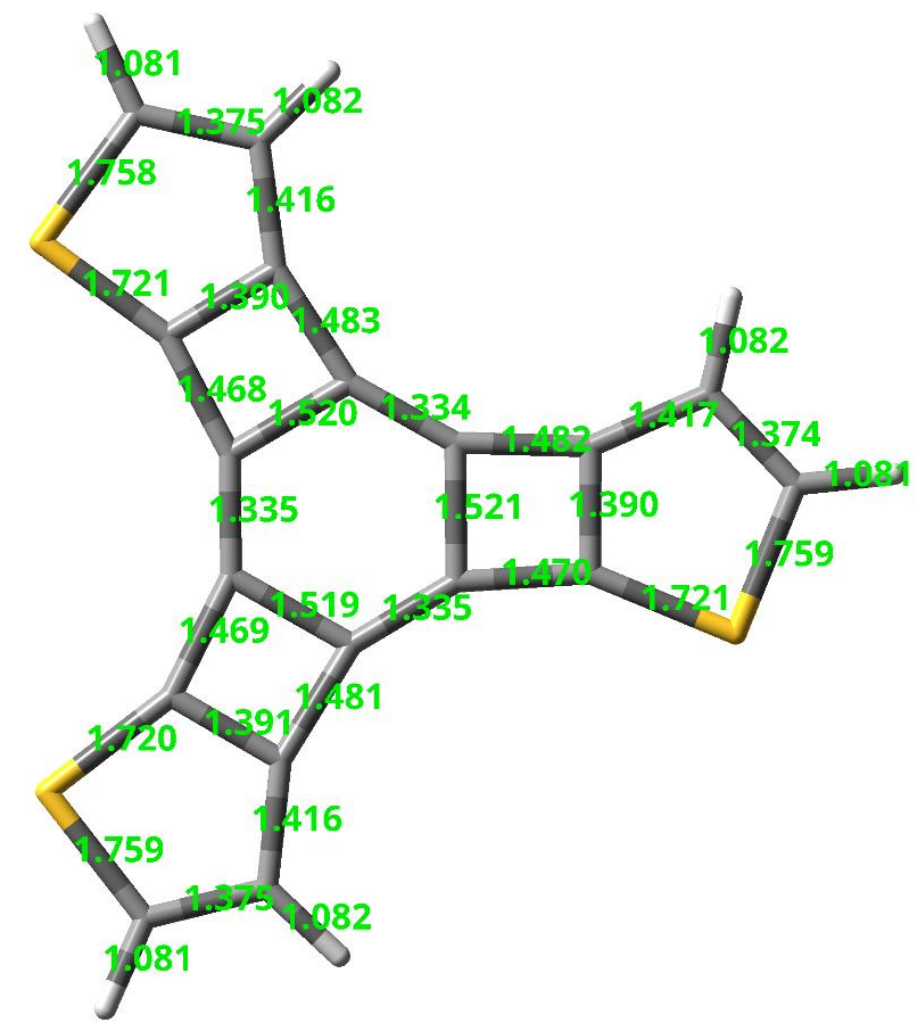

bB1

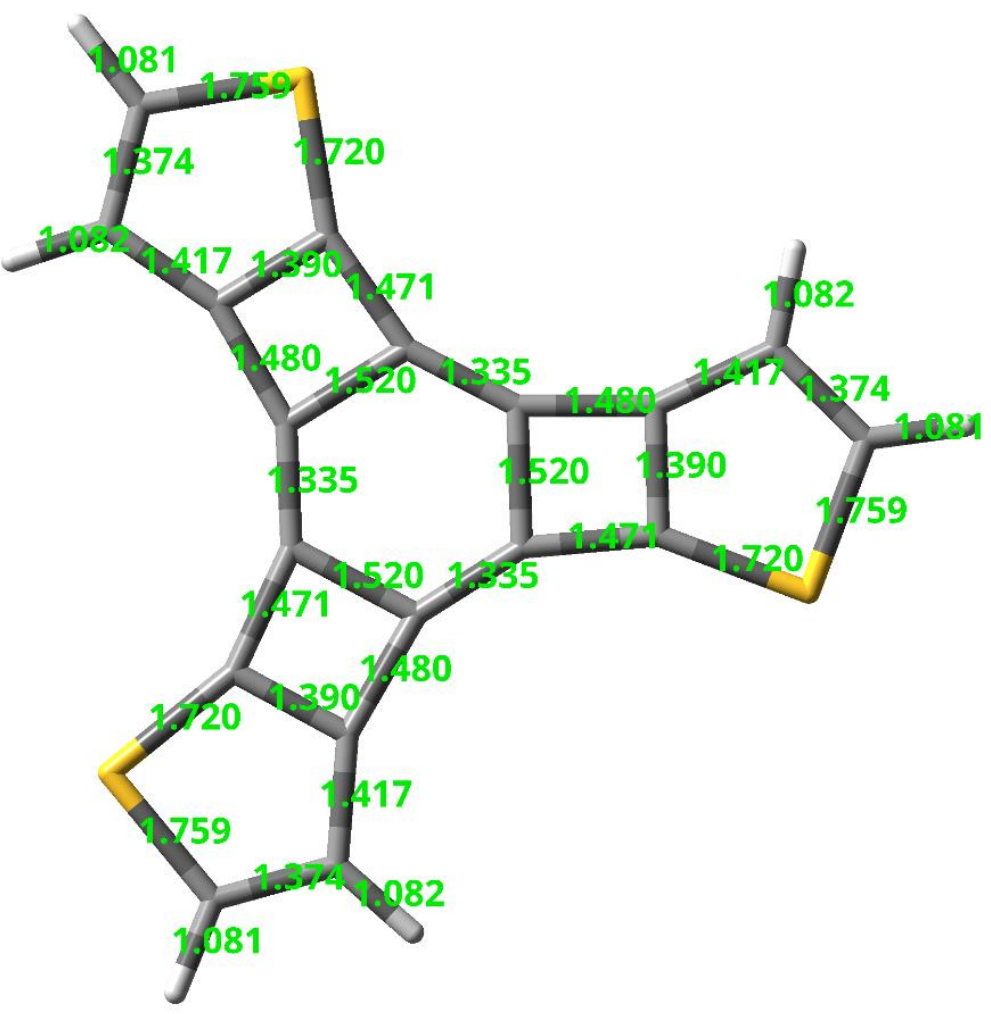

bB2

Figure S1 (Continued). Bond lengths of biphenylene, BCTs, their homologues, and $[N]$ phenylenes $(\AA)$. 


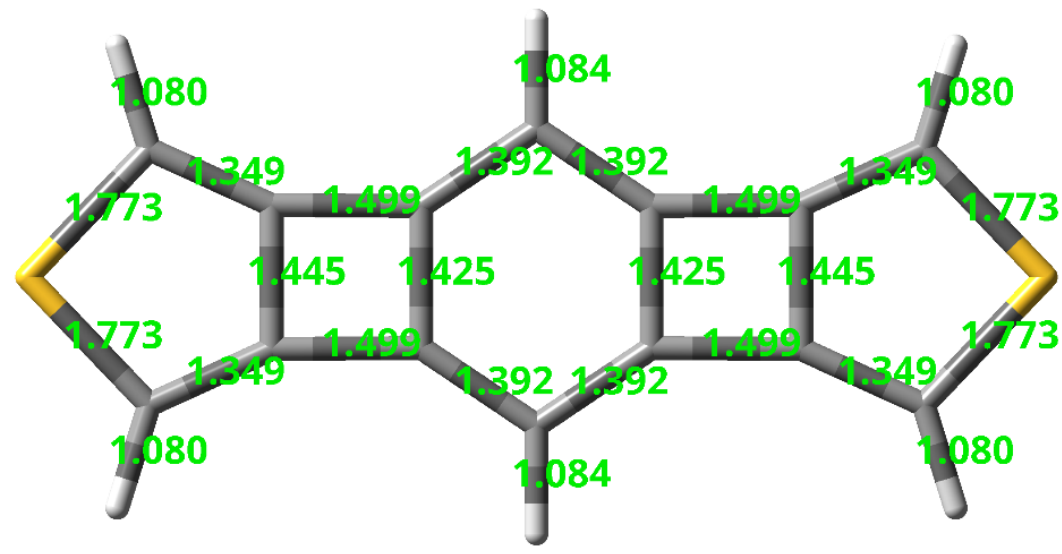

$c L$

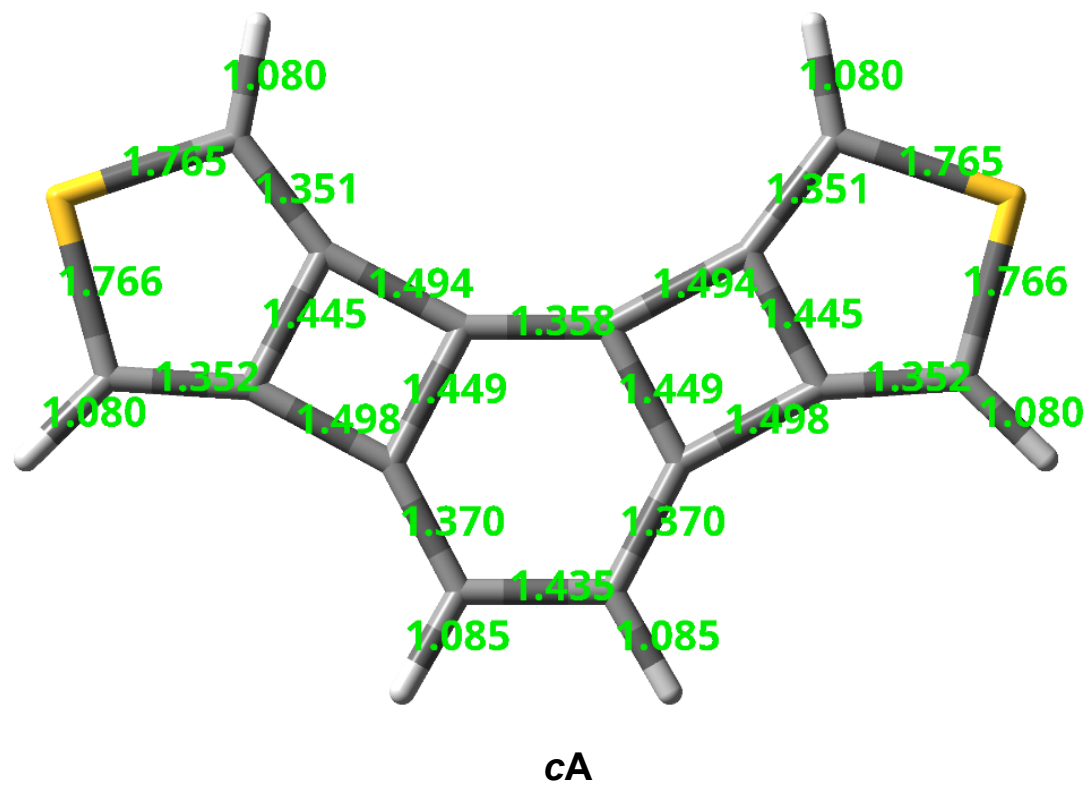

Figure S1 (Continued). Bond lengths of biphenylene, BCTs, their homologues, and $[N]$ phenylenes $(\AA)$. 

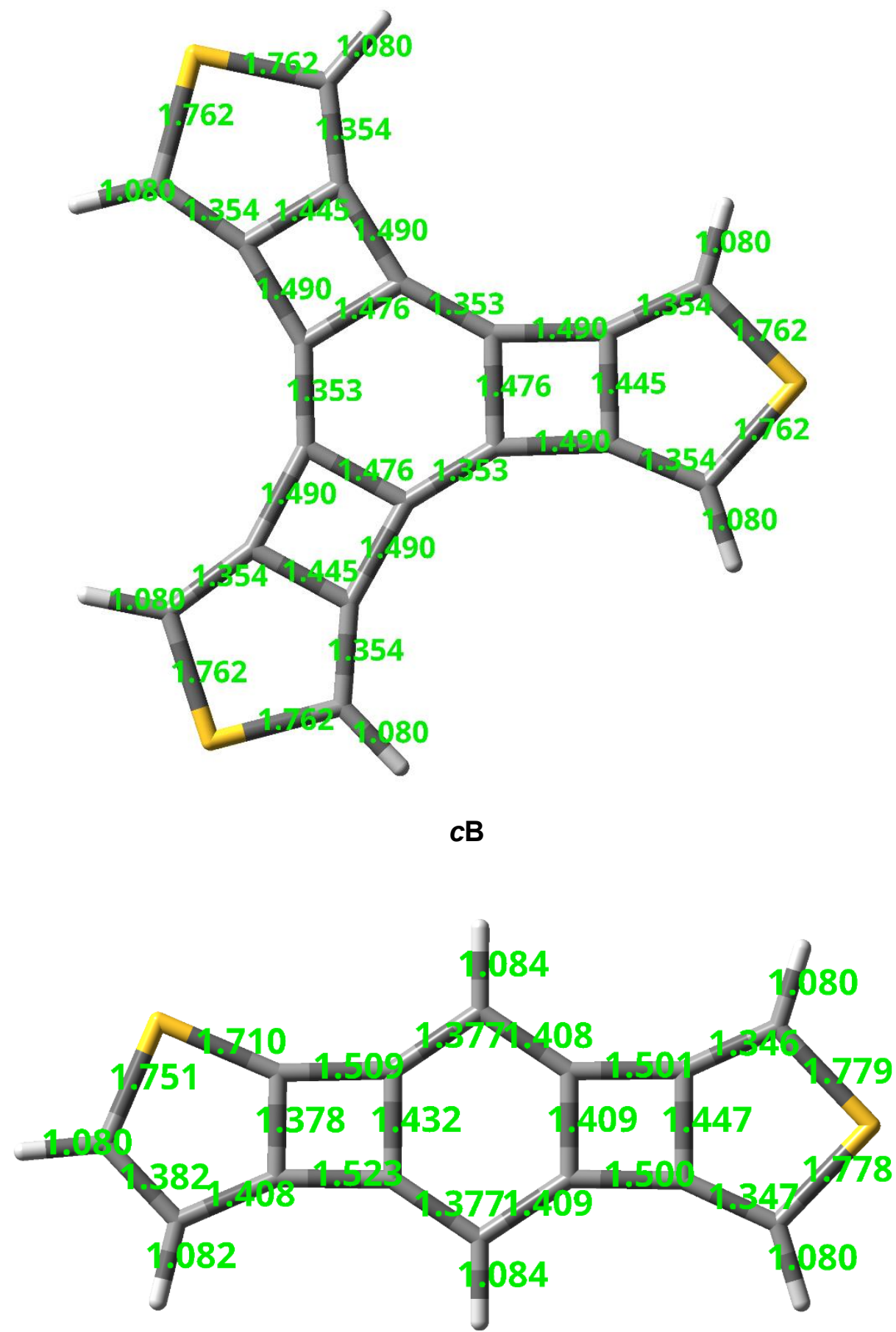

$b c L$

Figure S1 (Continued). Bond lengths of biphenylene, BCTs, their homologues, and $[N]$ phenylenes $(\AA)$. 


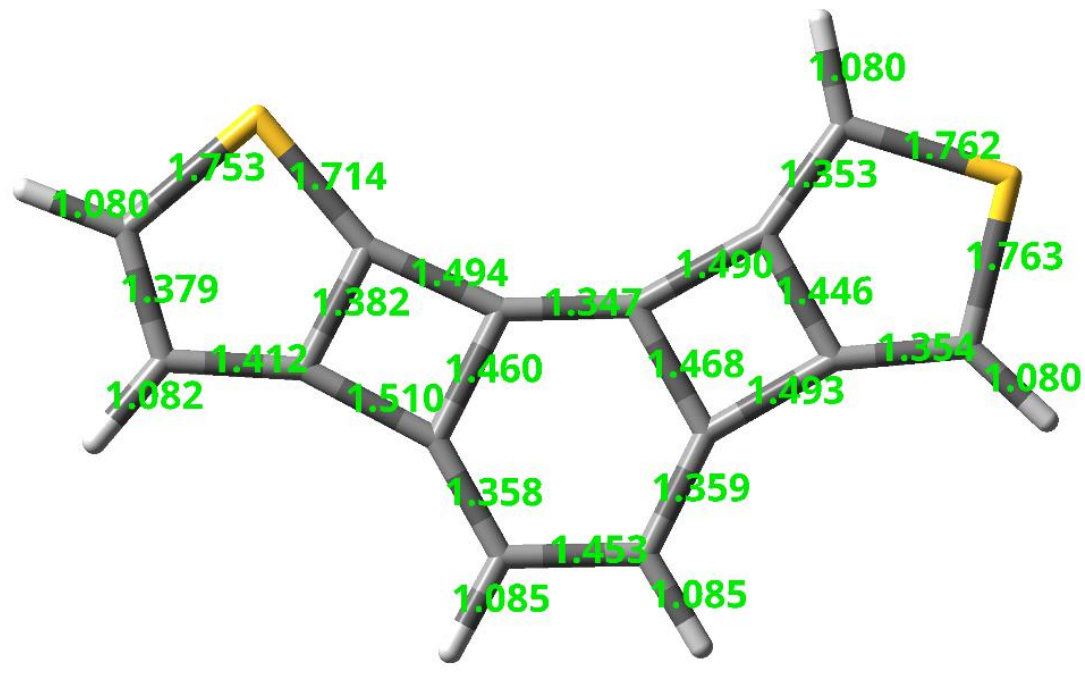

bcA1

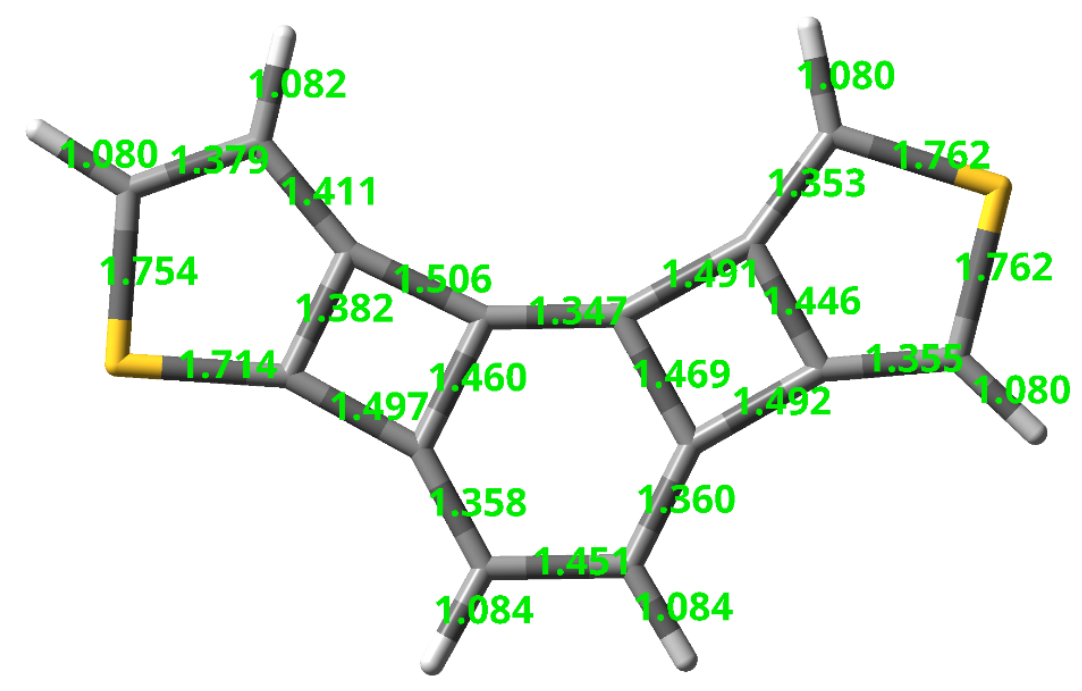

bcA2

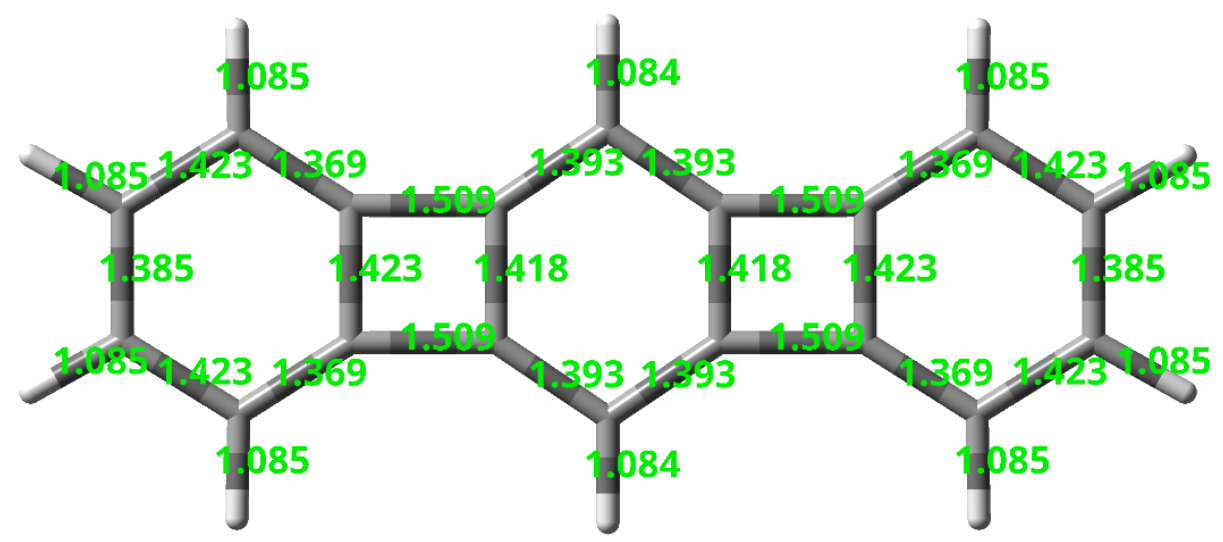

Linear [3]phenylene

Figure S1 (Continued). Bond lengths of biphenylene, BCTs, their homologues, and $[N]$ phenylenes $(\AA)$. 


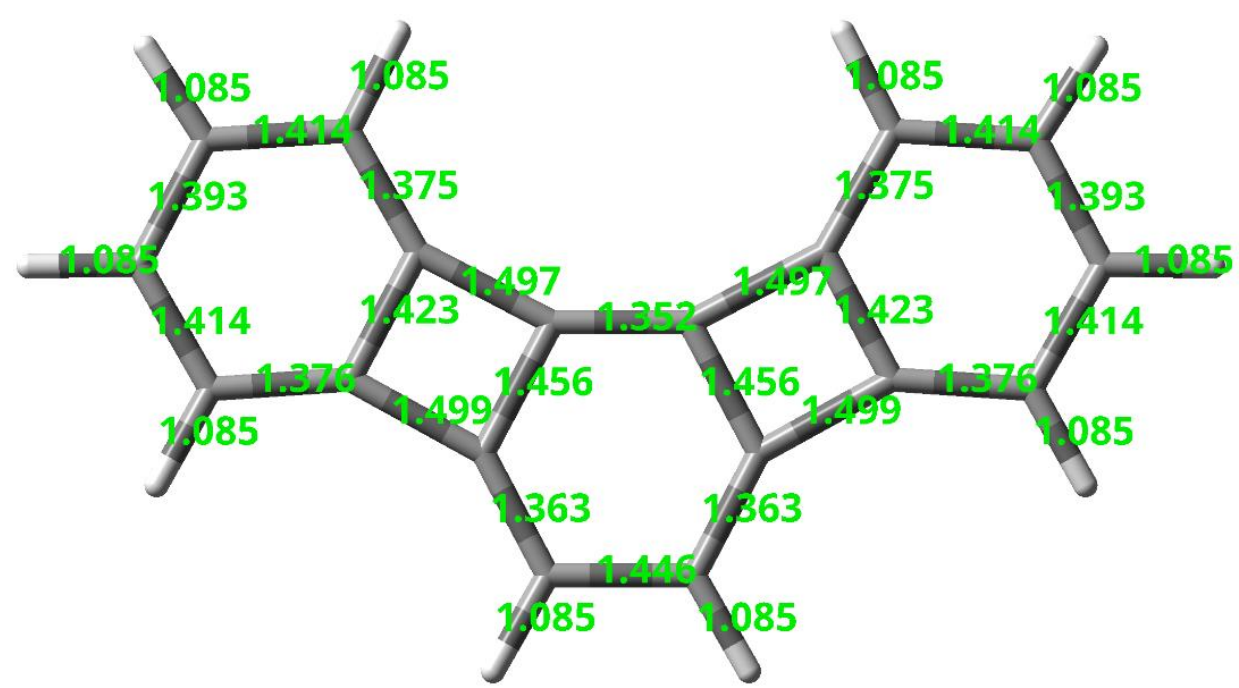

Angular [3]phenylene

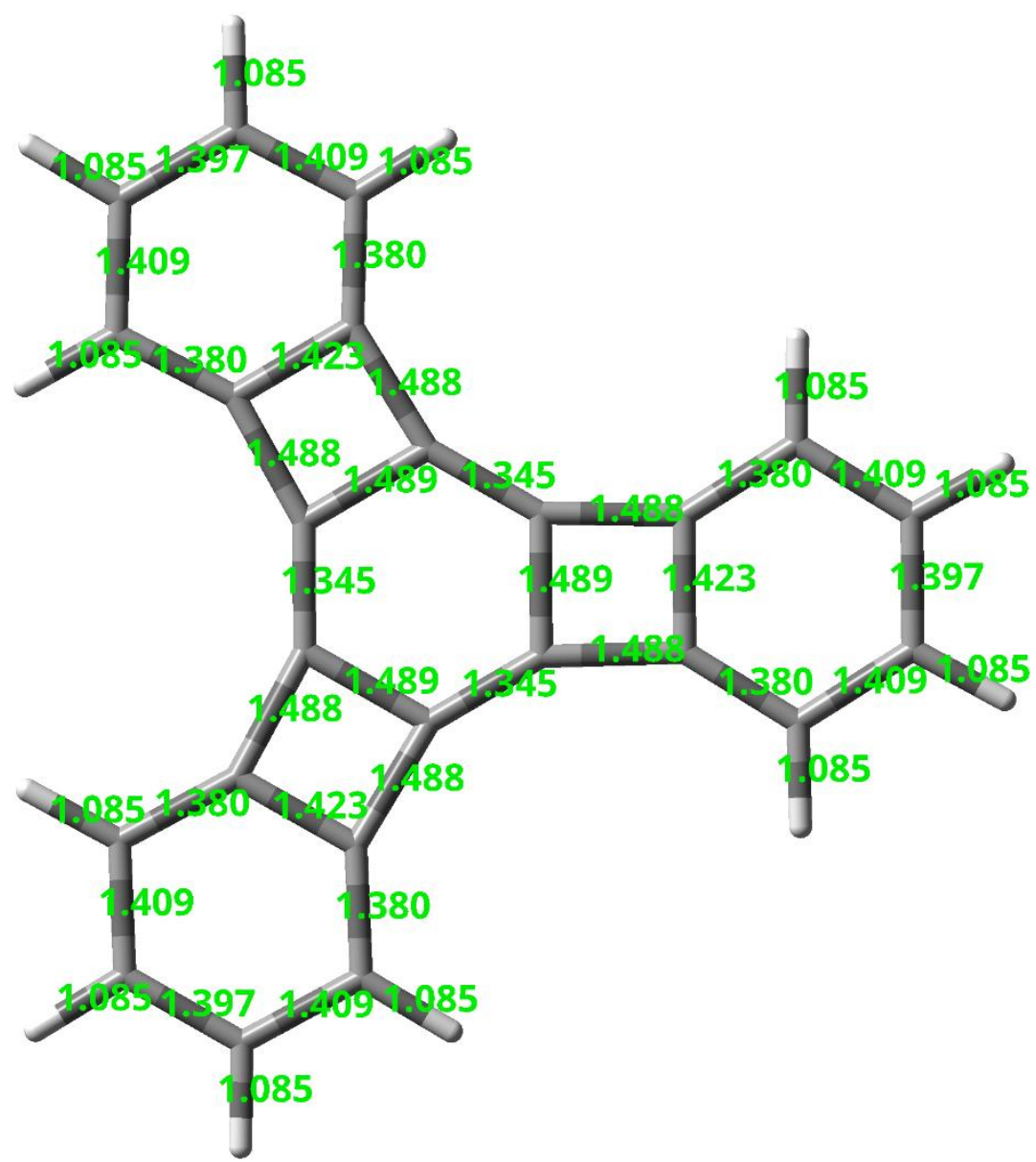

\section{Branched [4]phenylene}

Figure S1 (Continued). Bond lengths of biphenylene, BCTs, their homologues, and $[N]$ phenylenes $(\AA)$. 
3. HOMA and NICS values and AICD plots of benzene, thiophene, and cyclobutadiene

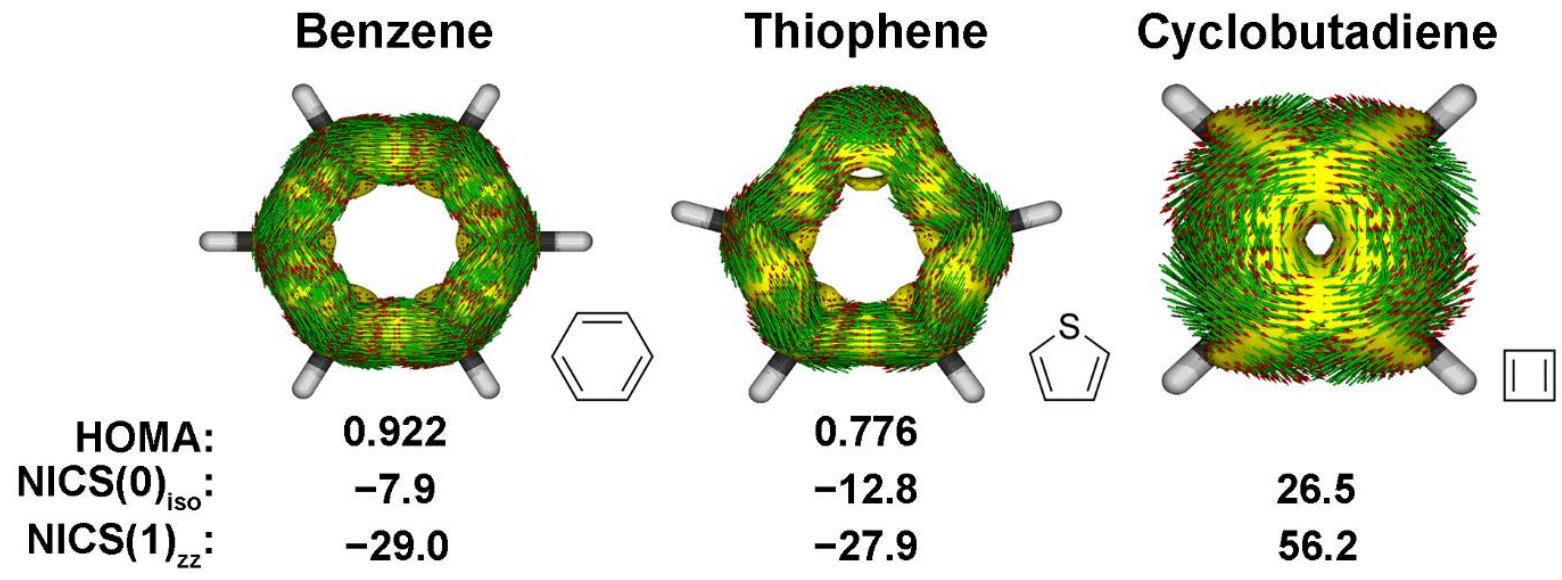

Figure S2. HOMA, NICS $(0)_{\text {iso }}(\mathrm{ppm})$, and $\operatorname{NICS}(1)_{z z}(\mathrm{ppm})$ values, as well as the AICD plots of benzene, thiophene, and cyclobutadiene (isovalues: 0.035). An external magnetic field was applied that is oriented perpendicular to the molecular plane pointing upward.

4. NICS- $X Y$ scans of biphenylene, $b \mathrm{BCT}$, and $c \mathrm{BCT}$

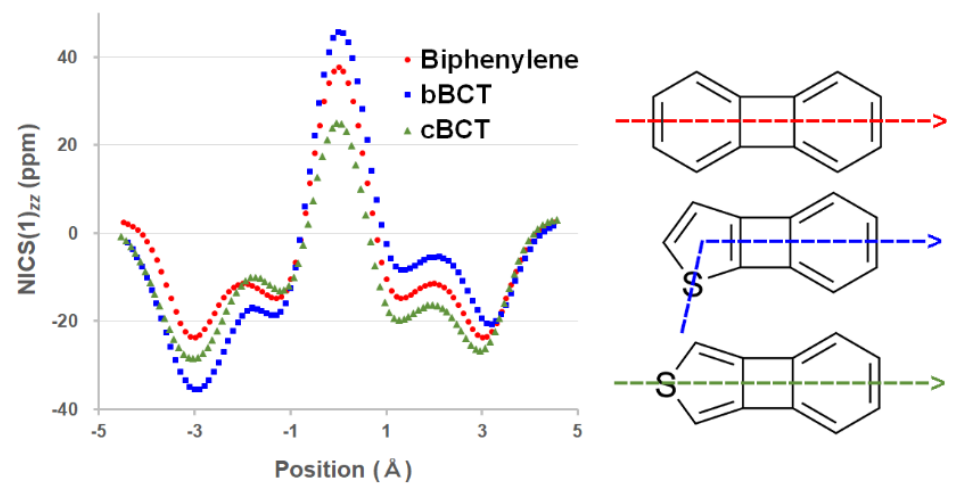

Figure S3. NICS- $X Y$ Scan $^{\mathrm{S} 1}$ plots of biphenylene, $b \mathrm{BCT}$ and $c \mathrm{BCT}$. Ghost atoms (Bq) are placed every $0.1 \AA$. 
5. NICS(0) iso values of biphenylene, BCTs, their homologues, and $[N]$ phenylenes except for the $b \mathrm{~L}-$ homologues

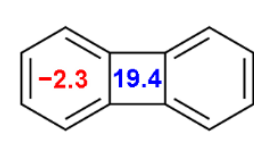

Biphenylene

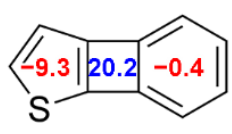

bBCT

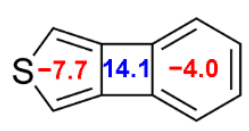

cBCT

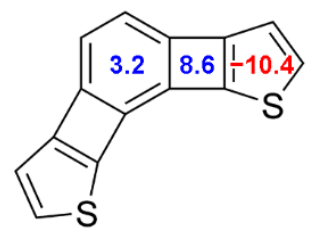

bA1

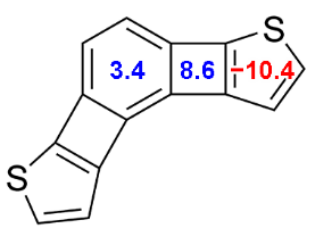

bA2

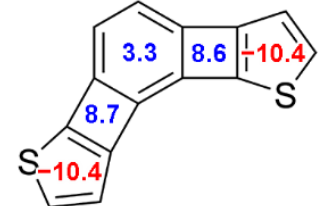

bA3

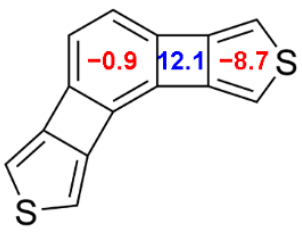

$c \mathrm{~A}$

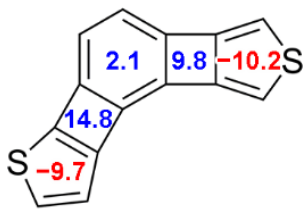

bcA2

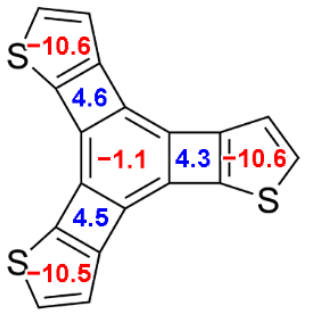

bB1

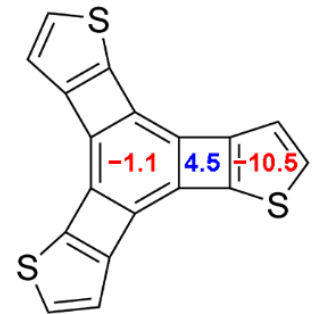

bB2

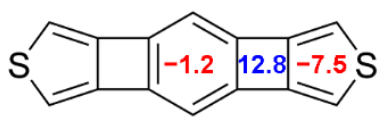

$c L$

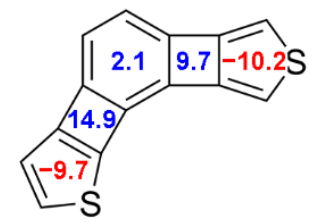

$b c L$

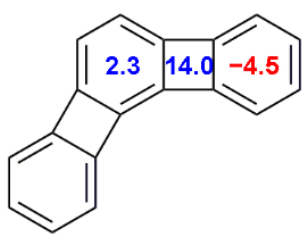

Angular [3]phenylene

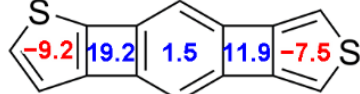

$-S$

bcA1

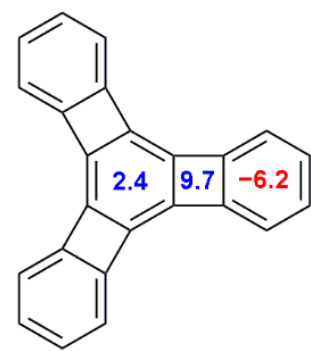

Branched [4]phenylene

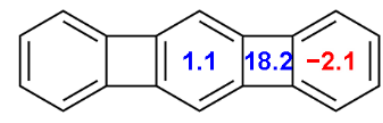

Linear [3]phenylene

Figure S4. NICS $(0)_{\text {iso }}$ (ppm; red or blue) values of biphenylene, BCTs, their homologues, and $[N]$ phenylenes except for the $b \mathrm{~L}$-homologues. 
6. The non-planar geometry of $b \mathrm{L1}$

(a)

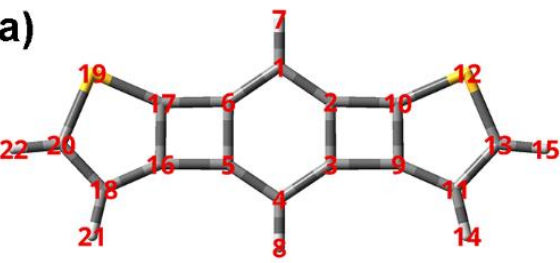

(b)

Figure S5. Top view (a) and side view (b) of $b$ L1. Dihedral angles of $10.34^{\circ}(1-2-10-12)$ and $8.30^{\circ}(4-3-9-11)$ were observed.

\section{Diradical character $y_{\mathrm{d}}$ values for BCTs, biphenylene, and their homologues}

Table S2. Diradical character $y_{\mathrm{d}}$ values for BCTs, biphenylene, and their homologues.

\begin{tabular}{cc}
\hline Compound & $y_{\mathrm{d}}$ \\
\hline$b \mathrm{BCT}$ & 0.12 \\
$c \mathrm{BCT}$ & 0.00 \\
$b \mathrm{~L} 1$ & 0.39 \\
$b \mathrm{~L} 2$ & 0.40 \\
$b \mathrm{~A} 1$ & 0.01 \\
$b \mathrm{~A} 2$ & 0.00 \\
$b \mathrm{~A} 3$ & 0.00 \\
$b \mathrm{~B} 1$ & 0.00 \\
$b \mathrm{~B} 2$ & 0.00 \\
$c \mathrm{~L}$ & 0.09 \\
$c \mathrm{~A}$ & 0.00 \\
$c \mathrm{~B}$ & 0.00 \\
$b c \mathrm{~L}$ & 0.22 \\
$b c \mathrm{~A} 1$ & 0.00 \\
$b c \mathrm{~A} 2$ & 0.01 \\
Biphenylene & 0.08 \\
Linear $[3]$ phenylene & 0.22 \\
Angular $[3]$ phenylene & 0.11 \\
Branched $[4]$ phenylene & 0.10 \\
\hline
\end{tabular}




\section{Spin-density distributions of the $b$ L-homologues}
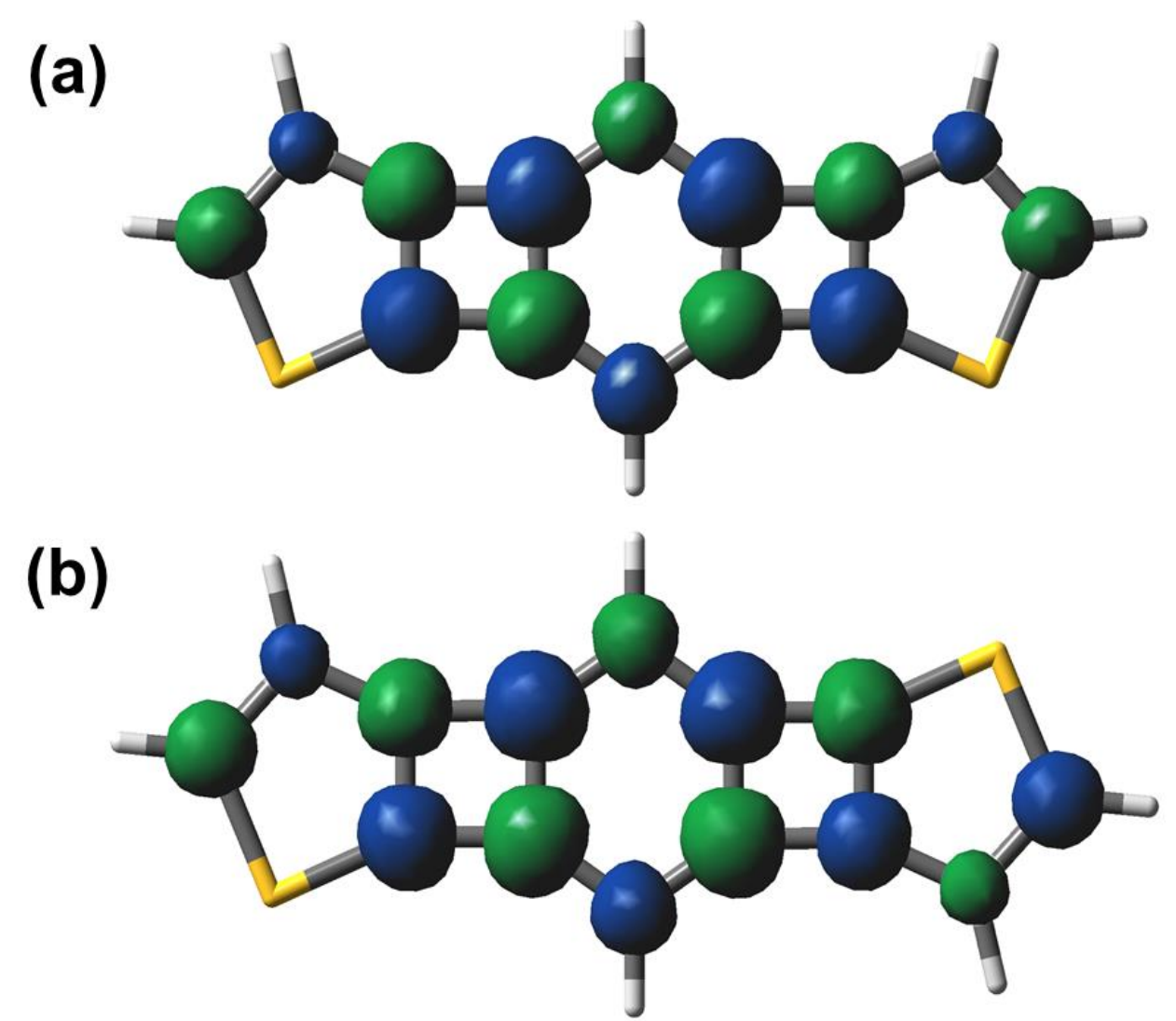

Figure S6. Spin-density distributions of $b \mathrm{~L} 1$ (a) and $b \mathrm{~L} 2$ (b) (isovalues: 0.006). Calculations were carried out at the UBHandHLYP/6-311+G(d) level of theory.

\section{Calculated current strength using GIMIC method}

To evaluate the induced current strength, the gauge-including magnetically induced current (GIMIC) program was used. ${ }^{59,60, \mathrm{~S} 2}$ The information of the atomic orbital (AO) density matrix, the first order perturbed AO density matrix, the molecular coordinates and the basis function were obtained from the magnetic shielding calculations using the B3LYP density functional theory level with the Karlsrush def2-TZVP basis set ${ }^{\mathrm{S} 3, \mathrm{~S} 4}$ employing the GIAO method. The input files for the GIMIC program were generated using the Gaussian2gimic.py program. ${ }^{\text {S5 }}$

Each current strength was calculated by numerical integration of the magnetically induced current density flowing across a plane perpendicularly to the molecular plane and bisecting chosen chemical bond. The one plane edge for the integration is located at the ring center and the plane extends outside until the current densities are negligible ( 8 bohr from the center of the bond). The current strength is given in $\mathrm{nAT}^{-1}$. A positive or negative current strength indicates diatropic or paratropic, respectively. An external magnetic field was applied perpendicularly to the molecular plane. In this study, the current strengths by the GIMIC calculations quantitatively agree with the NICS values and AICD plots. 


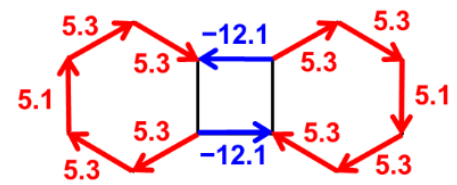

biphenylene

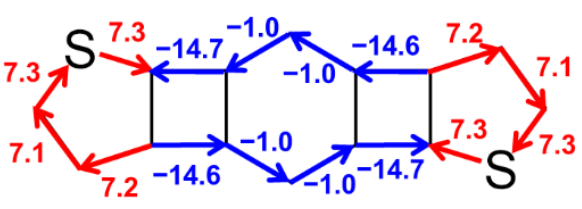

bL2

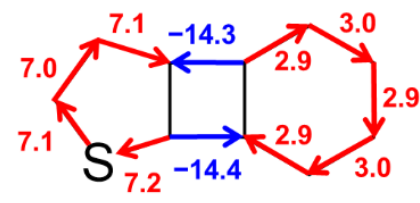

bBCT

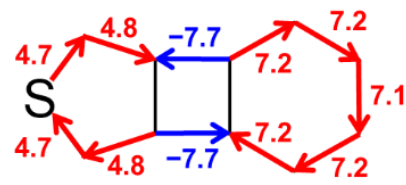

cBCT
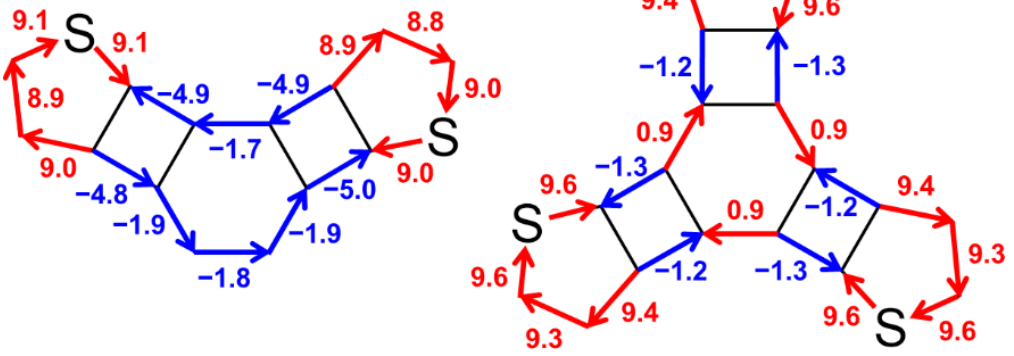

bA3

\section{bB2}
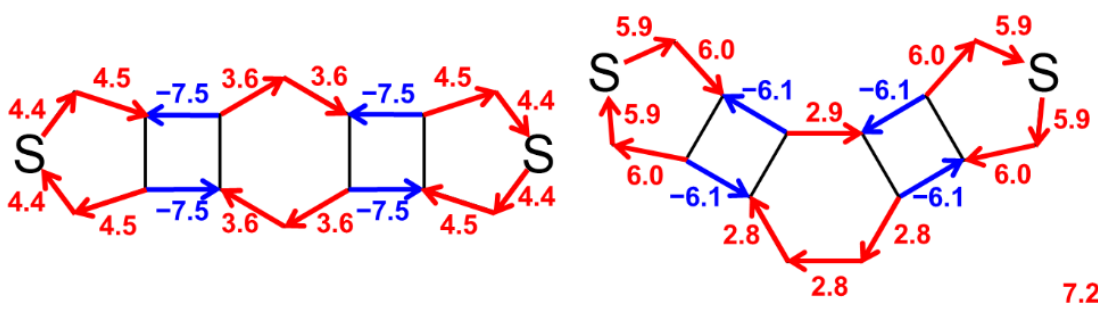

cL

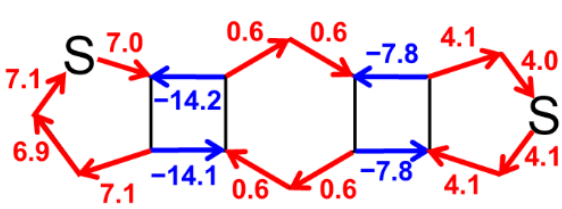

bcL

$c A$

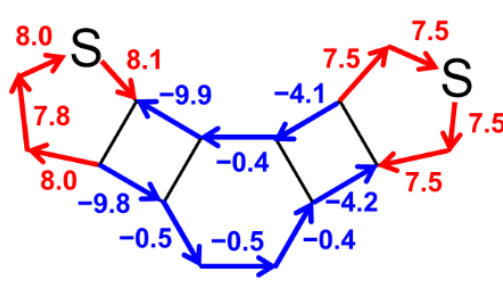

bcA1

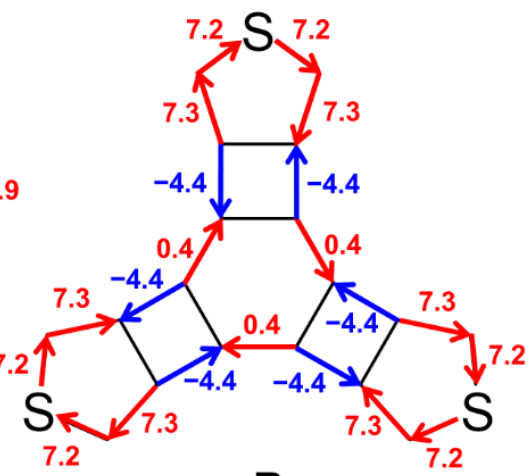

cB

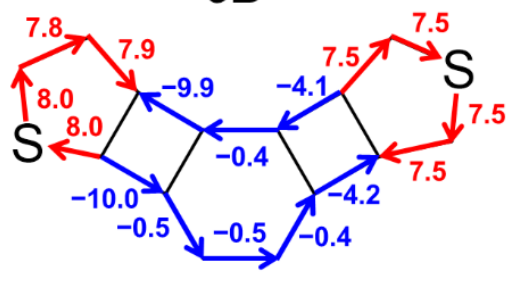

bcA2

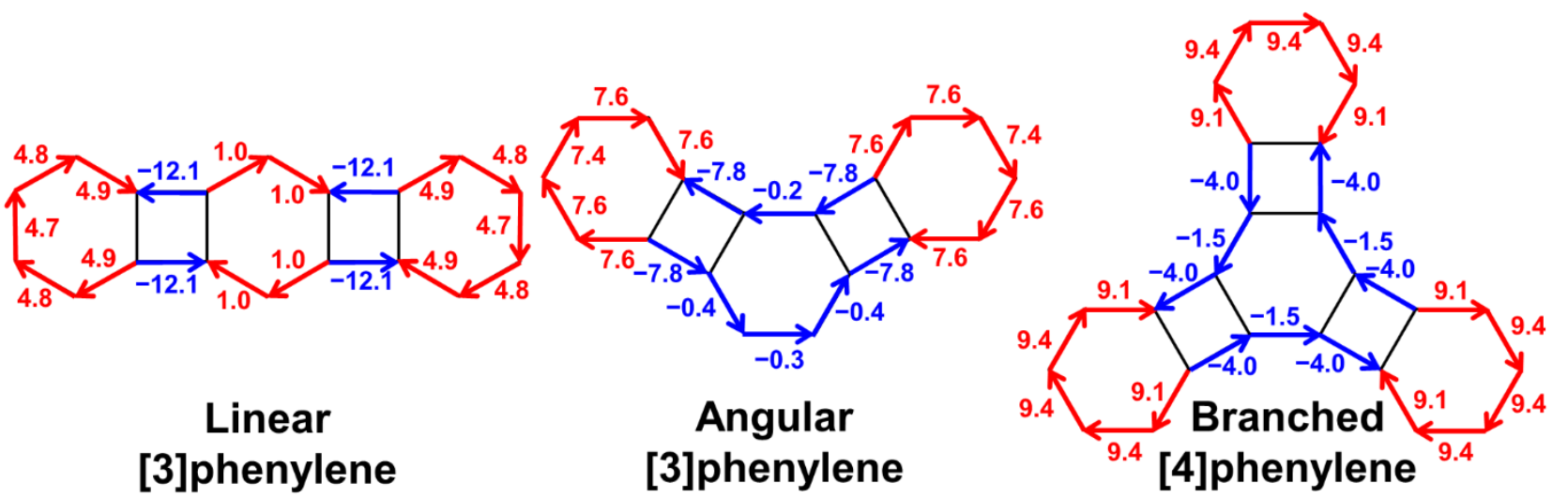

Figure S7. Calculated current strengths $\left(\mathrm{nAT}^{-1}\right)$ for biphenylene, BCTs, selected BCT homologues, and $[N]$ phenylenes. Red and blue arrows indicate clockwise (diatropic) and counter-clockwise (paratropic) current paths, respectively. 

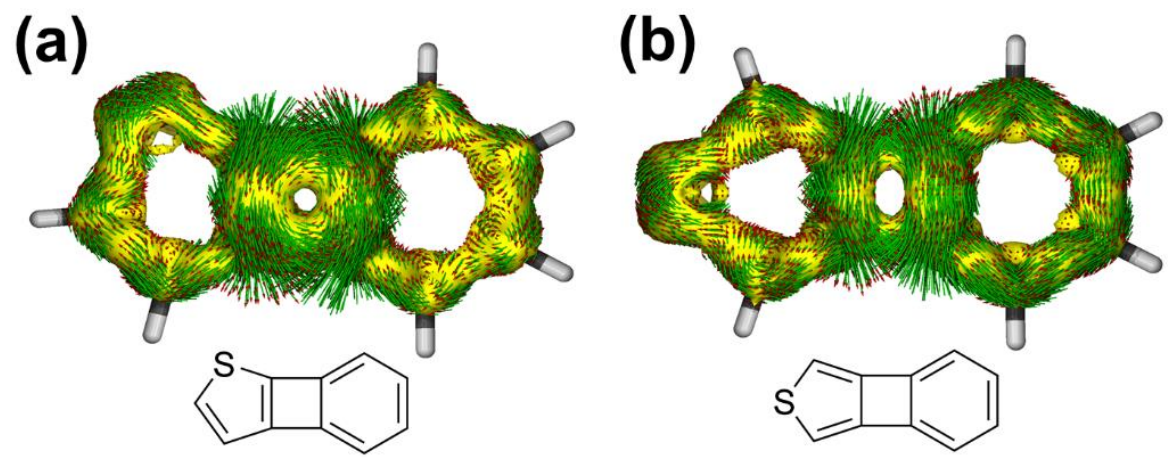

Figure S8. AICD plots calculated for (a) $b \mathrm{BCT}$ and (b) $c \mathrm{BCT}$ without arrows indicating current flows (isovalues: 0.035). An external magnetic field was applied that is oriented perpendicular to the molecular plane pointing upward.
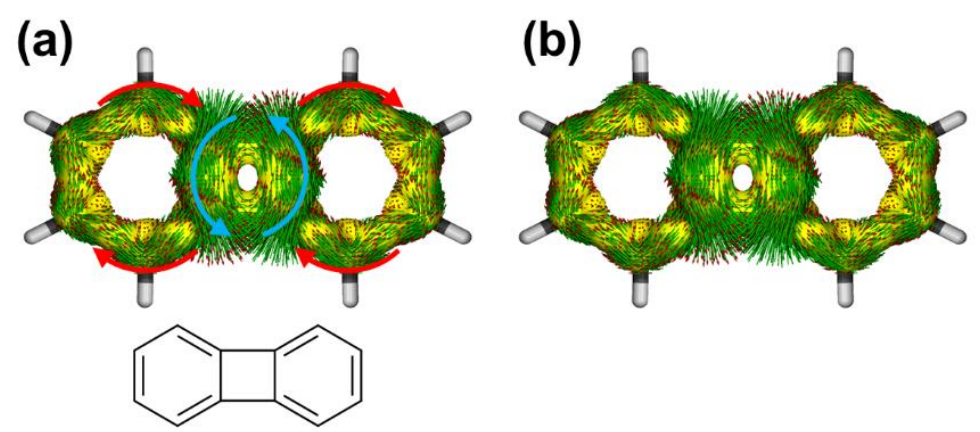

Figure S9. AICD plots calculated for biphenylene (a) with arrows and (b) without arrows (isovalues: 0.035). (a) Red and blue arrows indicate clockwise (diatropic) and counter-clockwise (paratropic) current flows. An external magnetic field was applied that is oriented perpendicular to the molecular plane pointing upward. 
(a)
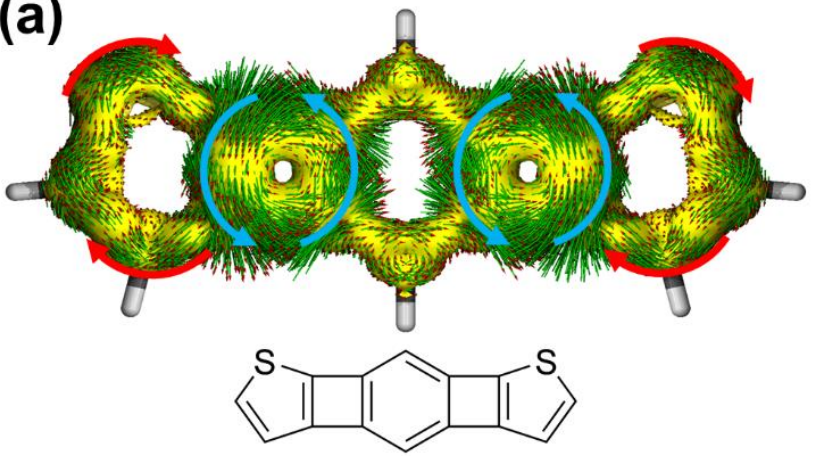

(c)

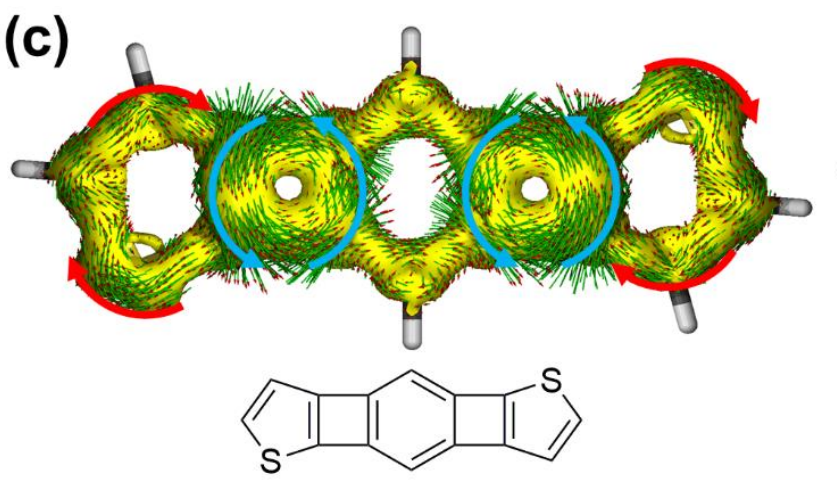

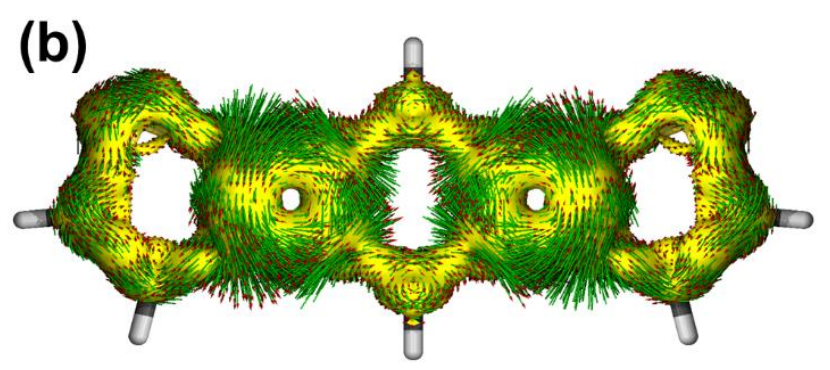

(d)

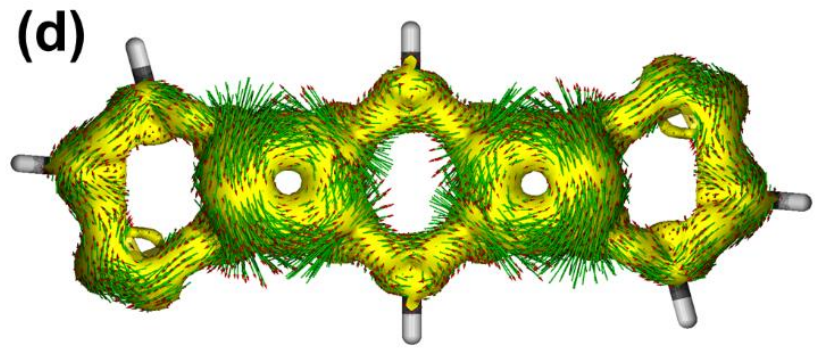

Figure S10. AICD plots calculated for (a, b) $b \mathrm{~L} 1$ and (c, d) $b \mathrm{~L} 2$ (isovalues: 0.035). (a, c) Red and blue arrows indicate clockwise (diatropic) and counter-clockwise (paratropic) current flows. An external magnetic field was applied that is oriented perpendicular to the molecular plane pointing upward. 
(a)

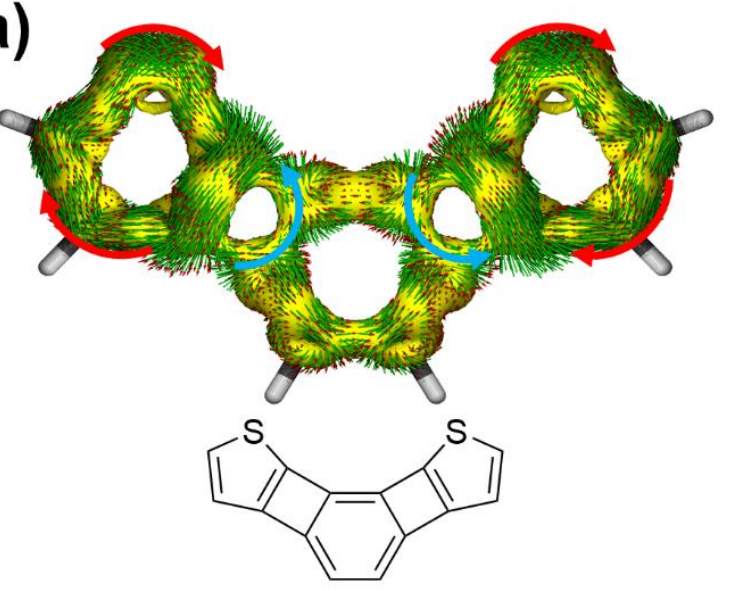

(c)

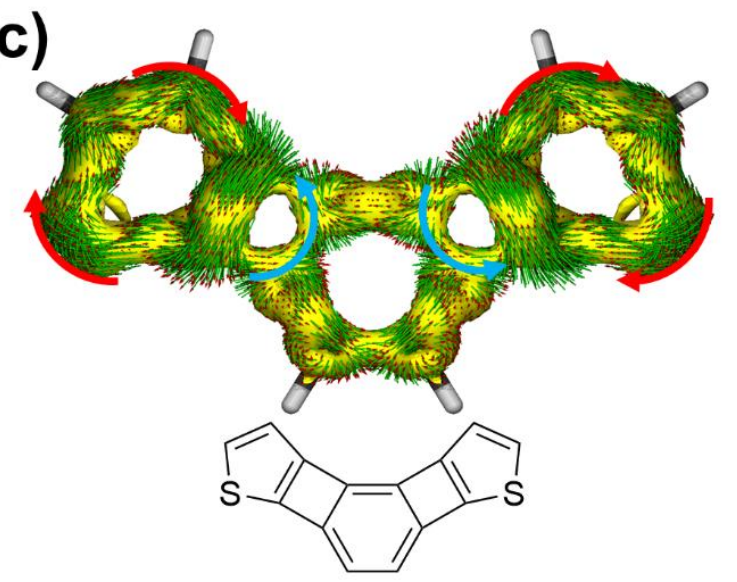

(e)

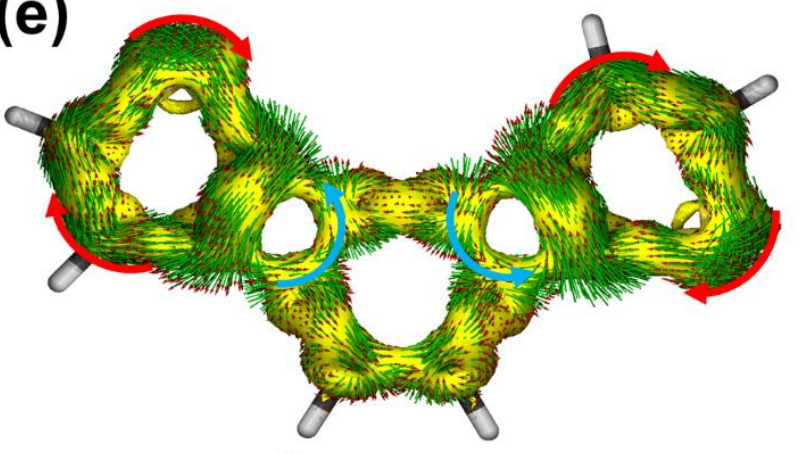<smiles>c1cc2c(s1)c1ccc3c4ccsc4c3c21</smiles>

(b)

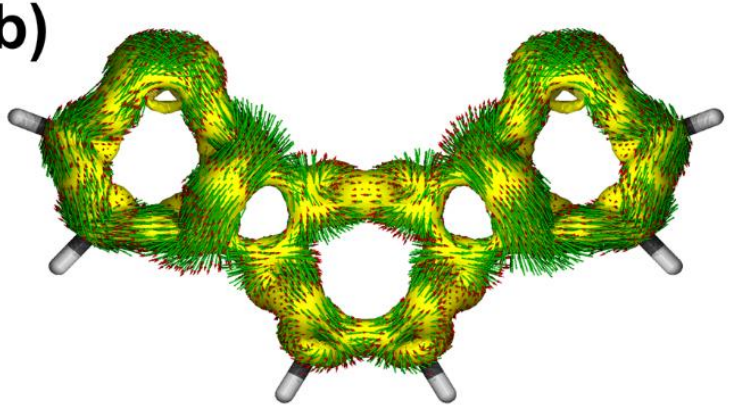

(d)

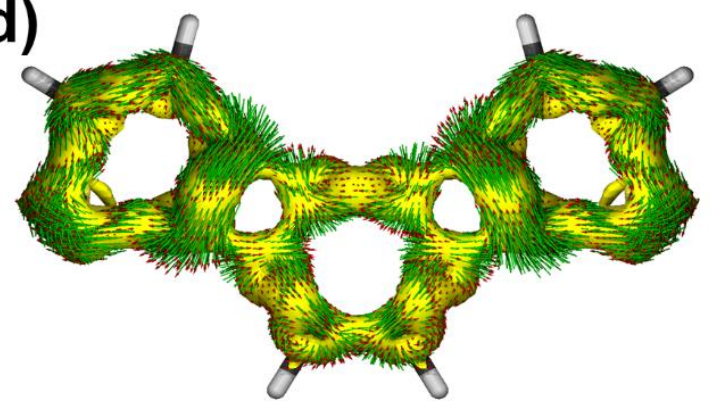

(f)

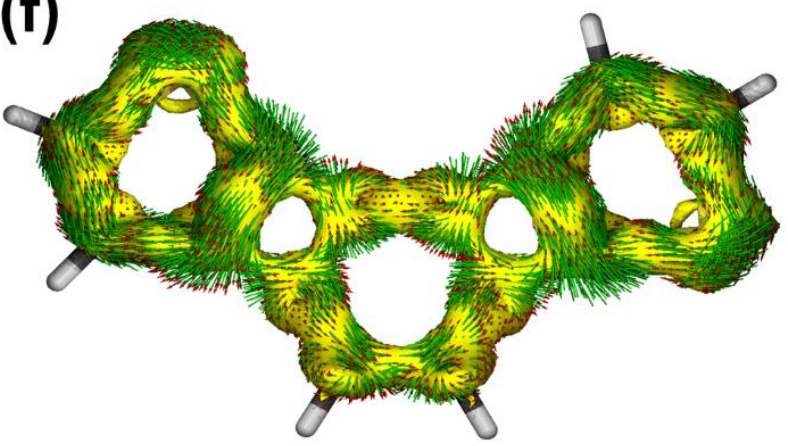

Figure S11. AICD plots calculated for (a, b) $b \mathrm{~A} 1$, (c, d) $b \mathrm{~A} 2$, and (e, f) $b \mathrm{~A} 3$ (isovalues: 0.035). (a, c, e) Red and blue arrows indicate clockwise (diatropic) and counter-clockwise (paratropic) current flows. An external magnetic field was applied that is oriented perpendicular to the molecular plane pointing upward. 

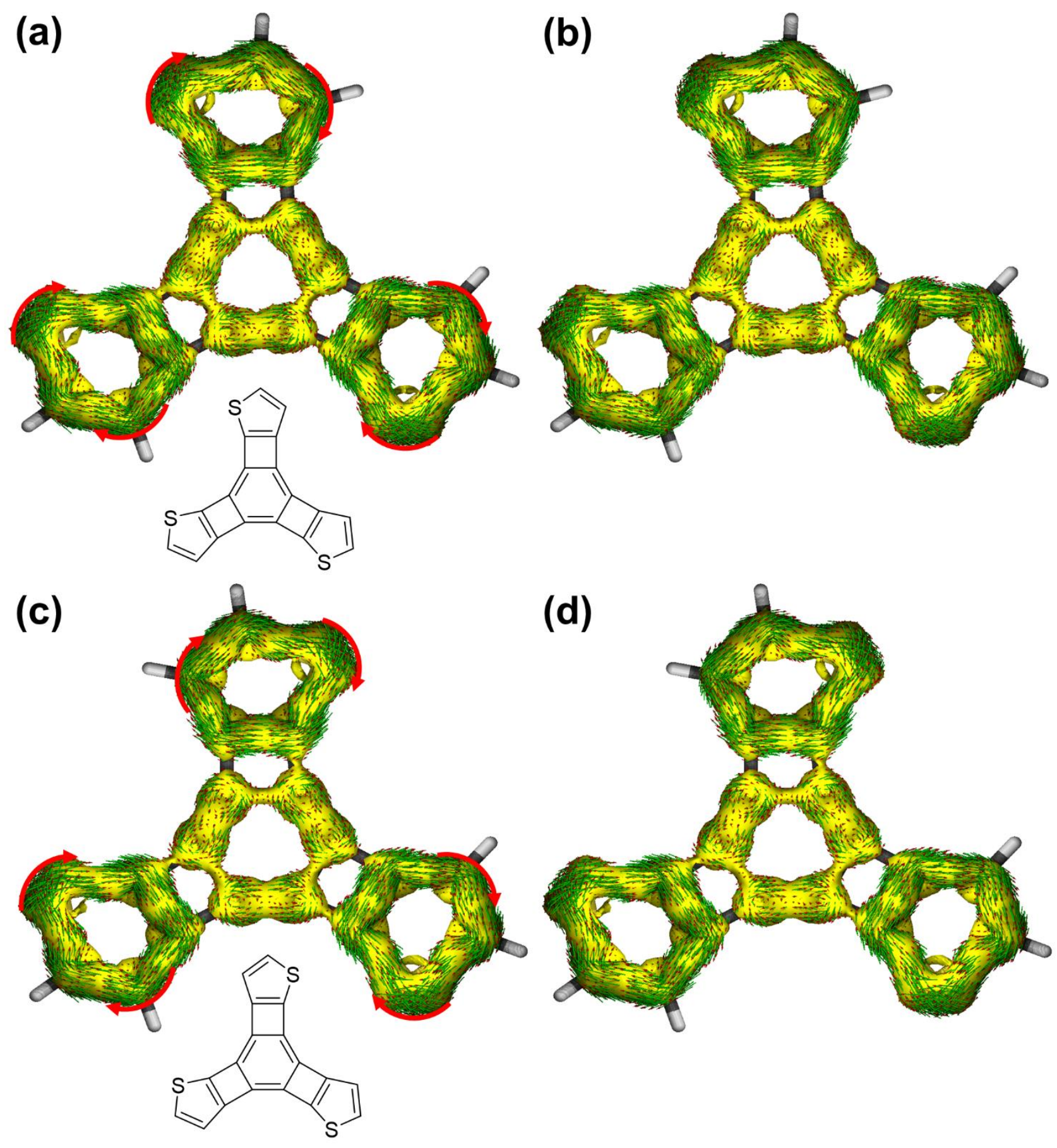

Figure S12. AICD plots calculated for (a, b) $b \mathrm{~B} 1$ and (c, d) $b \mathrm{~A} 2$ (isovalues: 0.035). (a, c) Red and blue arrows indicate clockwise (diatropic) and counter-clockwise (paratropic) current flows. An external magnetic field was applied that is oriented perpendicular to the molecular plane pointing upward. 


\section{AICD plots and NICS(0) iso value for 1,3 -cyclohexadiene}

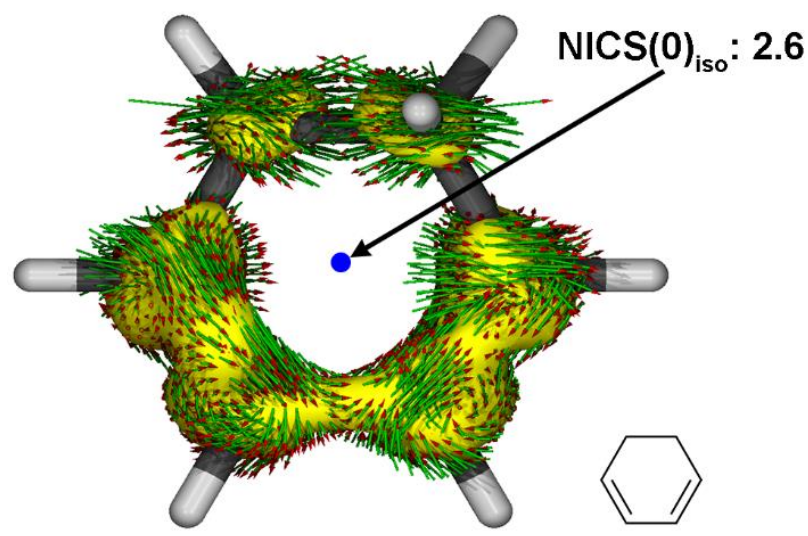

Figure S13. AICD plot and $\operatorname{NICS}(0)_{\text {iso }}$ value $(\mathrm{ppm})$ calculated for 1,3 -cyclohexadiene (isovalue: 0.035$) .{ }^{58} \mathrm{An}$ external magnetic field was applied that is oriented perpendicular to the molecular plane pointing upward.

\section{Discussion about the aromaticity of the $c$-homologues}

The central 6MR of $c$ L exhibits a two-fold rotational symmetry, and the lengths of the shared bonds (Figure $\mathrm{S} 1)$ are longer than those of the $b \mathrm{~L}$-homologues (Table 1). This is due to a strong single-bond character of the fused bonds in the thiophene rings. The bond lengths for the $6 \mathrm{MRs}$ of $c \mathrm{~A}$ and $c \mathrm{~B}$ (Figure $\mathrm{S} 1$ ) indicate decreased BLAs compared to the corresponding $b$-homologues. The HOMA values of the 6MRs are $0.770(c \mathrm{~L}), 0.395$ $(c \mathrm{~A})$, and $-0.335(c \mathrm{~B}$; Figure 4). Those of the thiophene rings increase in the same order: $0.419(c \mathrm{~L}), 0.475$ $(c \mathrm{~A})$, and $0.507(c \mathrm{~B})$.

The NICS value for $6 \mathrm{MR}$ of $c \mathrm{~L}$ is less negative than that of $c \mathrm{BCT}$, while the 4MRs and thiophene rings show NICS values that are almost identical to those of $c \mathrm{BCT}$, which is due to attenuating cyclic conjugation in the linear-type isomer (Figure 4). The AICD plot of $c \mathrm{~L}$, however, shows a weakened diatropic ring current in the 6MR (Figures S14a, b). For $c \mathrm{~A}$, both the diatropicity of the $6 \mathrm{MR}$ and the paratropicity of the 4MRs are decreased, while the diatropicity of the thiophene rings are increased relative to those of $c \mathrm{BCT}$ and $c \mathrm{~L}$. According to an AICD plot (Figures $\mathrm{S} 14 \mathrm{c}, \mathrm{d}$ ), the thiophene rings of $c \mathrm{~A}$ exhibit an apparent diatropic ring current compared to those of $c \mathrm{BCT}$ and $c \mathrm{~L}$. Moreover, there is a weak diatropic ring current in the 6MR in contrast to the $b \mathrm{~A}$-homologues, where contributions of the conjugated diene and the localized double bonds are dominant (please refer to the main text). The NICS values of $c \mathrm{~B}$ show a tendency that is similar to $c \mathrm{~A}$.

In the $c$-homologues, the diatropic and paratropic character of the central $6 \mathrm{MRs}$ and the 4MRs decrease in the order: linear-, angular- and branched-type homologues, which is similar to the $b$-homologues. The thiophene rings of $c \mathrm{~B}$ are more diatropic compared to those of $c \mathrm{~A}$, while a significant difference between the $b \mathrm{~A}$ - and $b \mathrm{~B}$-homologues was not observed. The 4MRs of $c \mathrm{BCT}$ and $c \mathrm{~L}$ show smaller NICS values than 
those of the $b$-isomers. On the other hand, the 4MRs of $c \mathrm{~A}$ and $c \mathrm{~B}$ show larger NICS values than those of $b \mathrm{~A}$ and $b \mathrm{~B}$-homologues.
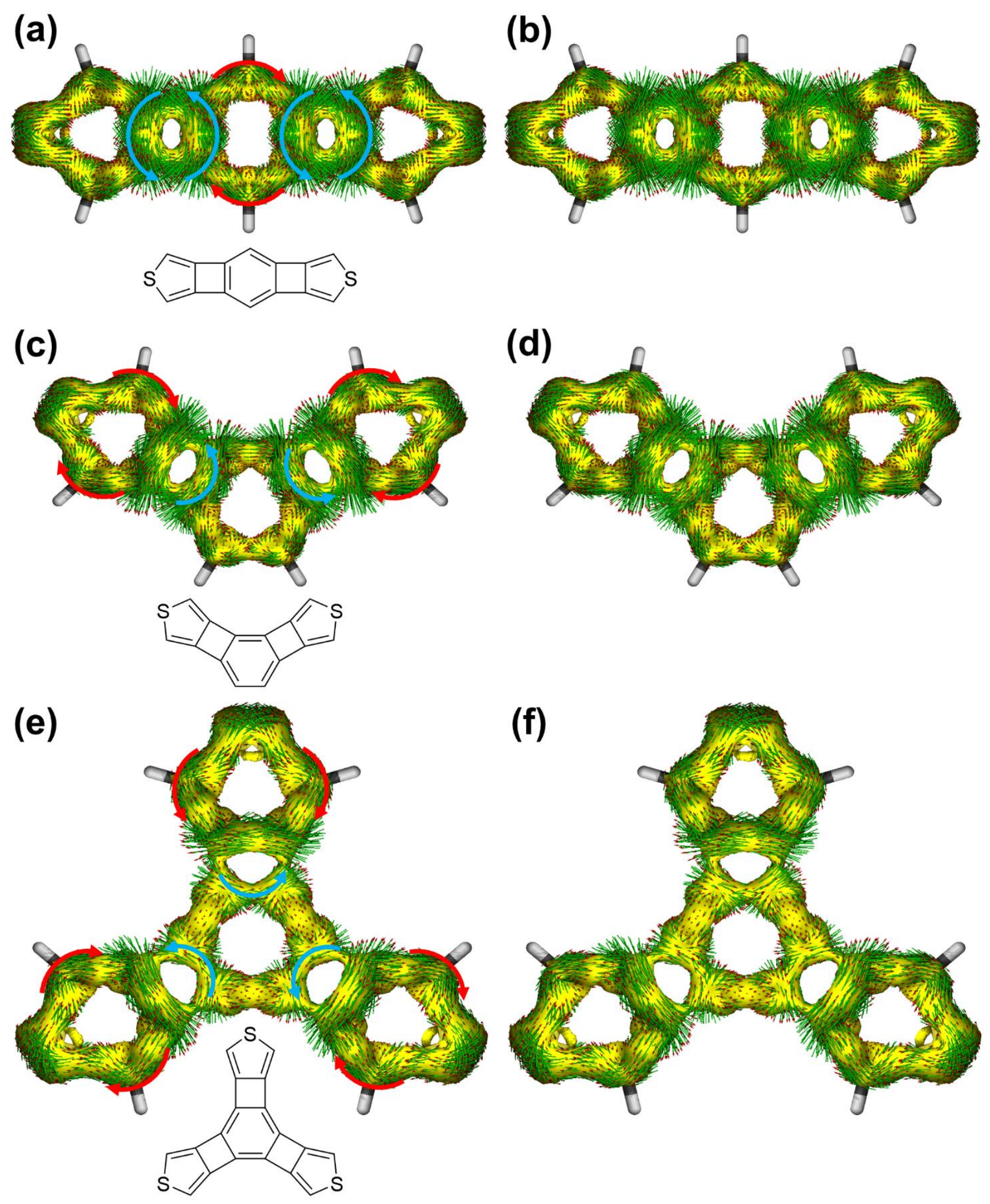

Figure S14. AICD plots calculated for $(\mathrm{a}, \mathrm{b}) c \mathrm{~L},(\mathrm{c}, \mathrm{d}) c \mathrm{~A}$, and (e, f) $c \mathrm{~B}$ (isovalues: 0.035). (a, c, e) Red and 
blue arrows indicate clockwise (diatropic) and counter-clockwise (paratropic) current flows. An external magnetic field was applied that is oriented perpendicular to the molecular plane pointing upward. $(a, b)$ In the case of cL, only weak diatropic ring current in the thiophene ring were observed.

\section{Discussion about the aromaticity of $b c$-homologues}

Since the different thiophenocyclobutadieno moieties are fused, the central 6MR of $b c \mathrm{~L}$ does not have twofold rotational symmetry. The HOMA value for the $6 \mathrm{MR}$ of $b c \mathrm{~L}$ is slightly smaller than that of $c \mathrm{~L}$.

The bond lengths of the central 6MRs of the $b c \mathrm{~A}$-homologues are intermediate between the those of the $b \mathrm{~A}$-homologues and $c \mathrm{~A}$. The HOMA values for the $6 \mathrm{MRs}$ of $b c \mathrm{~A}$-homologues are intermediate between $b \mathrm{~A}$ homologues and $c \mathrm{~A}$.

For all $b c$-homologues, their $b$ - and $c$-type thiophene rings adopt almost the same bond lengths as those of corresponding $b$ - and $c$-homologues. As a result, the HOMA values for the $b$ - and $c$-type thiophene rings of $b c \mathrm{~L}$ and $b c \mathrm{~A}$-homologues are almost the same to those of corresponding topological $b$-and $c$-homologues.

The NICS values for the $b$ - and $c$-type thiophenocyclobutadieno moieties of $b c \mathrm{~L}$ are very close to those of the thiophenocyclobutadieno moieties of $b \mathrm{~L}$-homologues and $c \mathrm{~L}$, respectively. Moreover, the $6 \mathrm{MR}$ of $b c \mathrm{~L}$ also exhibits an intermediate NICS value. In the case of $b c \mathrm{~A}$-homologues, the NICS values for the 6MRs are intermediate between those of $b \mathrm{~A}$-homologues and $c \mathrm{~A}$ as well. In contrast, the NICS values of the $b$ - and $c$-type four-membered rings of $b c \mathrm{~A}$-homologues indicate the strongest and weakest paratropicity among the angular homologues, respectively. The NICS values for the $b$-type thiophene rings are similar to those of $b \mathrm{~A}$ homologues and more negative over those of $c \mathrm{~A}$. The AICD plots (Figure S15) and the calculated current strengths (Figure S7) supported the NICS analyses. 
(a)
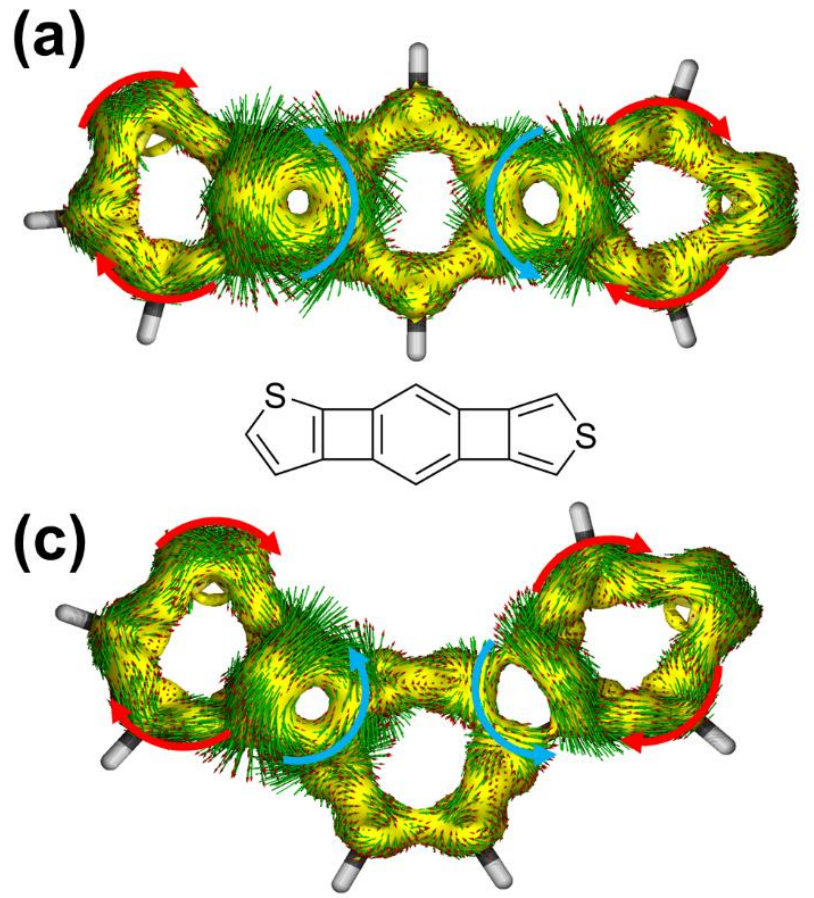<smiles>c1cc2c3ccc4c5cscc5c4c3c2s1</smiles>

(e)

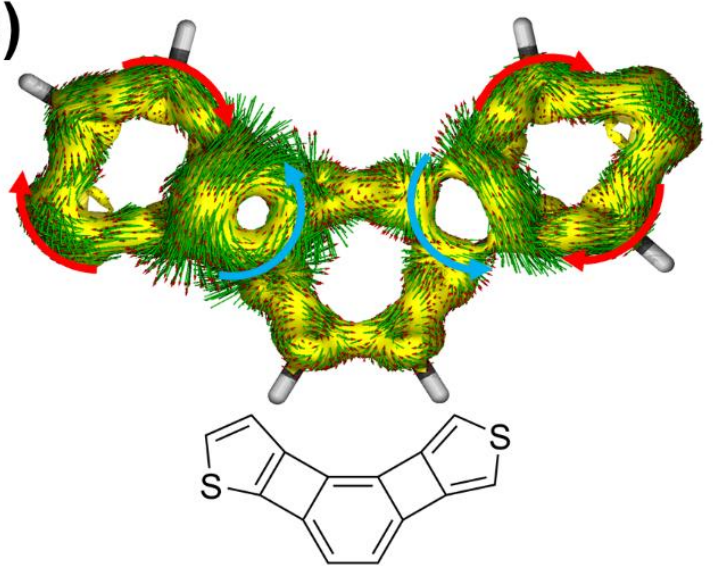

(b)

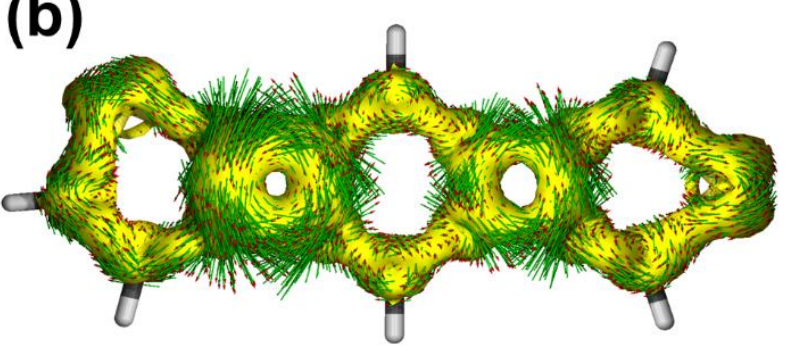

(d)

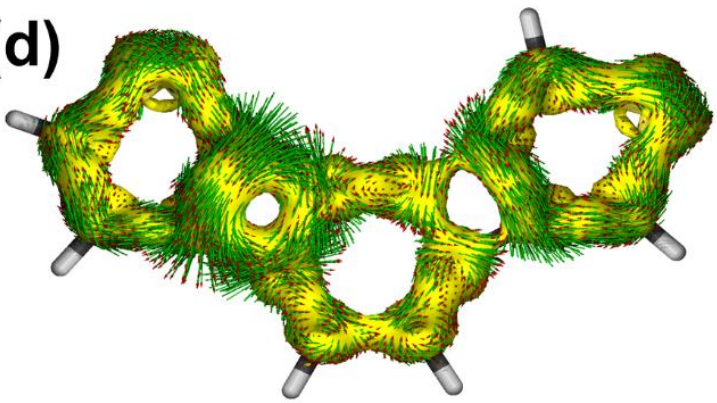

(f)

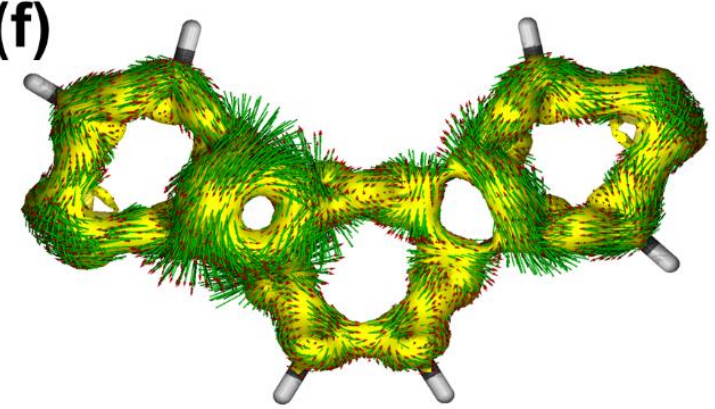

Figure S15. AICD plots calculated for (a, b) $b c \mathrm{~L}$, (c, d) $b c \mathrm{~A} 1$, and (e, f) $b c \mathrm{~A} 2$ (isovalues: 0.035). (a, c, e) Red and blue arrows indicate clockwise (diatropic) and counter-clockwise (paratropic) current flows. An external magnetic field was applied that is oriented perpendicular to the molecular plane pointing upward. 
14. AICD plots of $[N]$ phenylenes

(a)

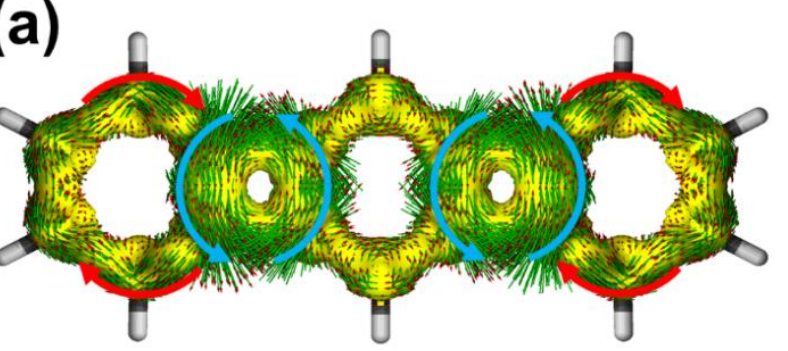<smiles>c1ccc2c(c1)c1cc3c4ccccc4c3cc21</smiles>

(c)

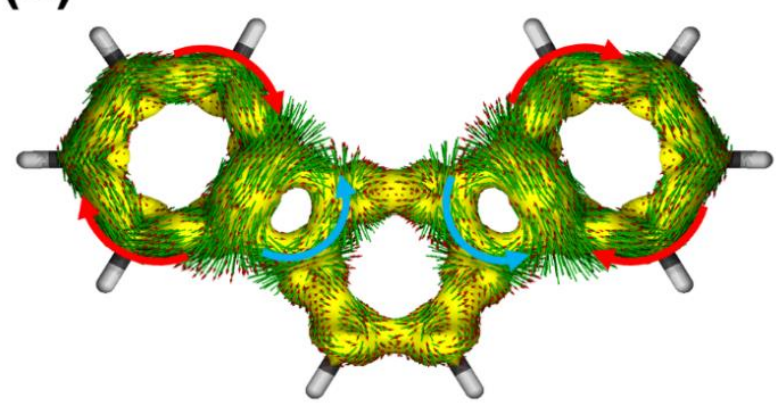

(e)<smiles>C1CC2CCC3CC(C1)C23</smiles>

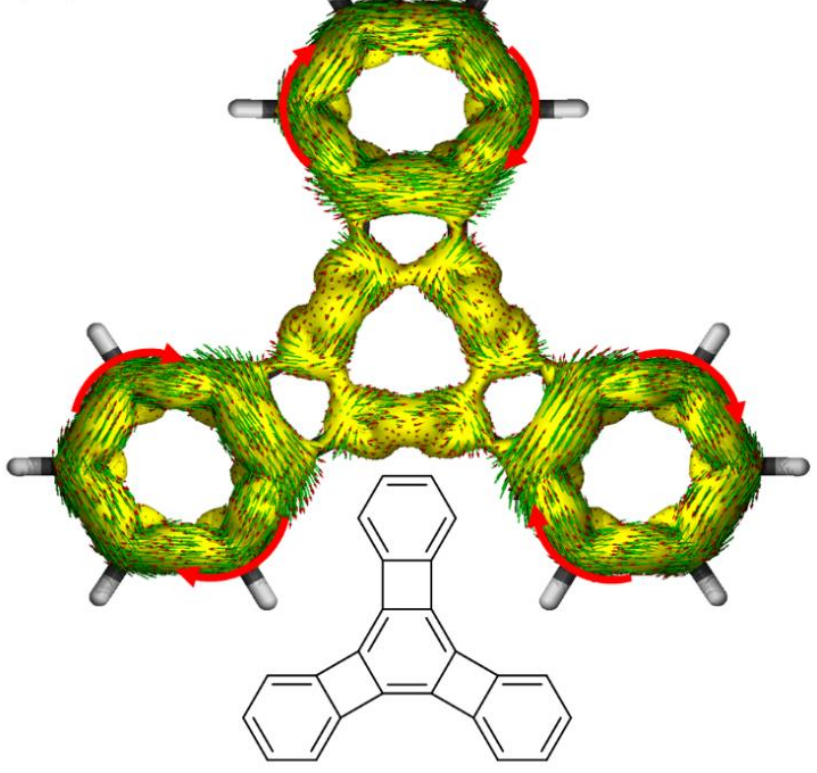

(b)

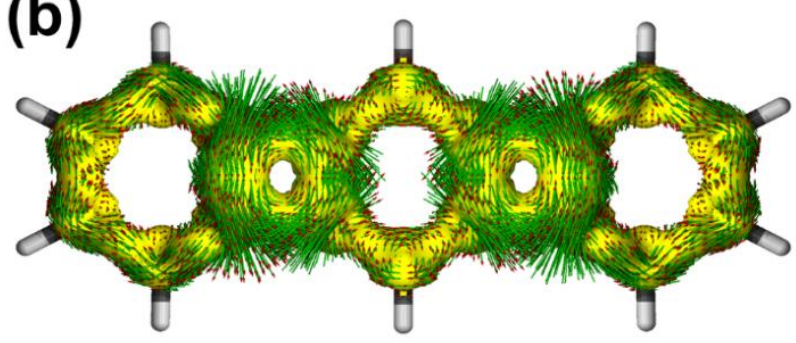

(d)

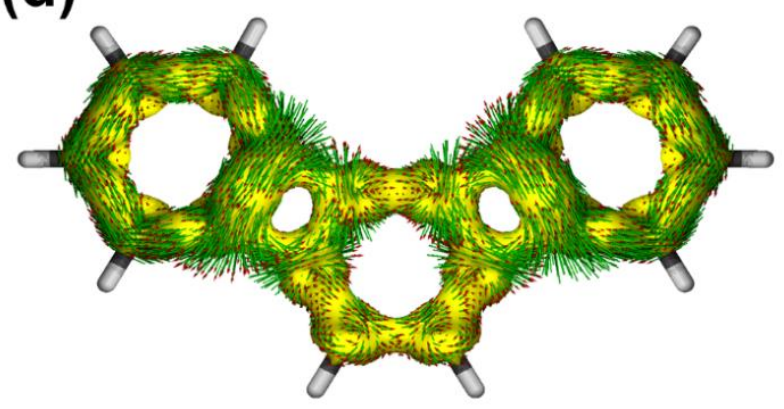

(f)

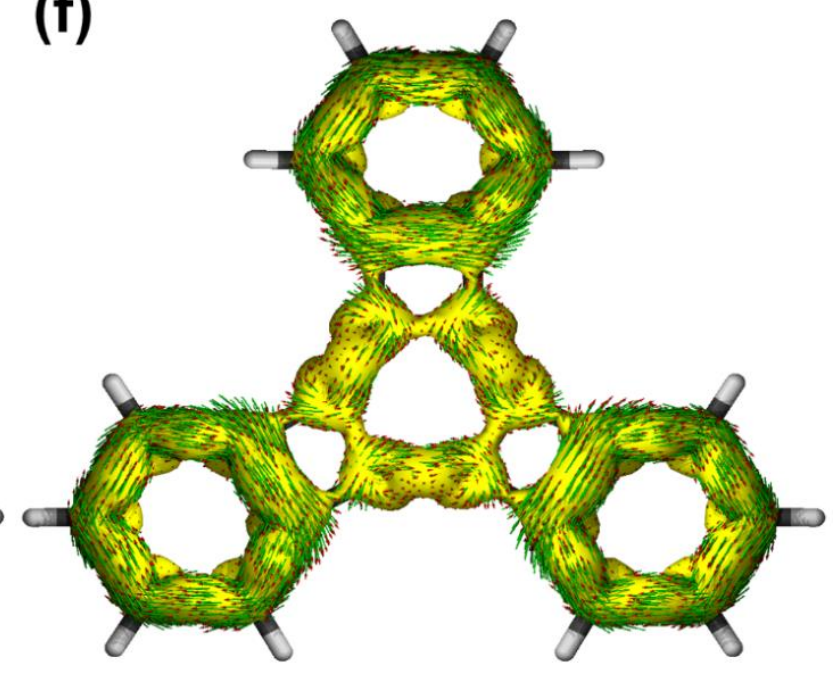

Figure S16. AICD plots calculated for (a, b) linear [3]phenylene, (c, d) angular [3]phenylene, and (e, f) branched [4]phenylene (isovalues: 0.035). (a, c, e) Red and blue arrows indicate clockwise (diatropic) and counterclockwise (paratropic) current flow. An external magnetic field was applied that is oriented perpendicular to the molecular plane pointing upward. 
15. Molecular orbitals of biphenylene and BCTs, and the frontier orbital distributions of the BCT homologues

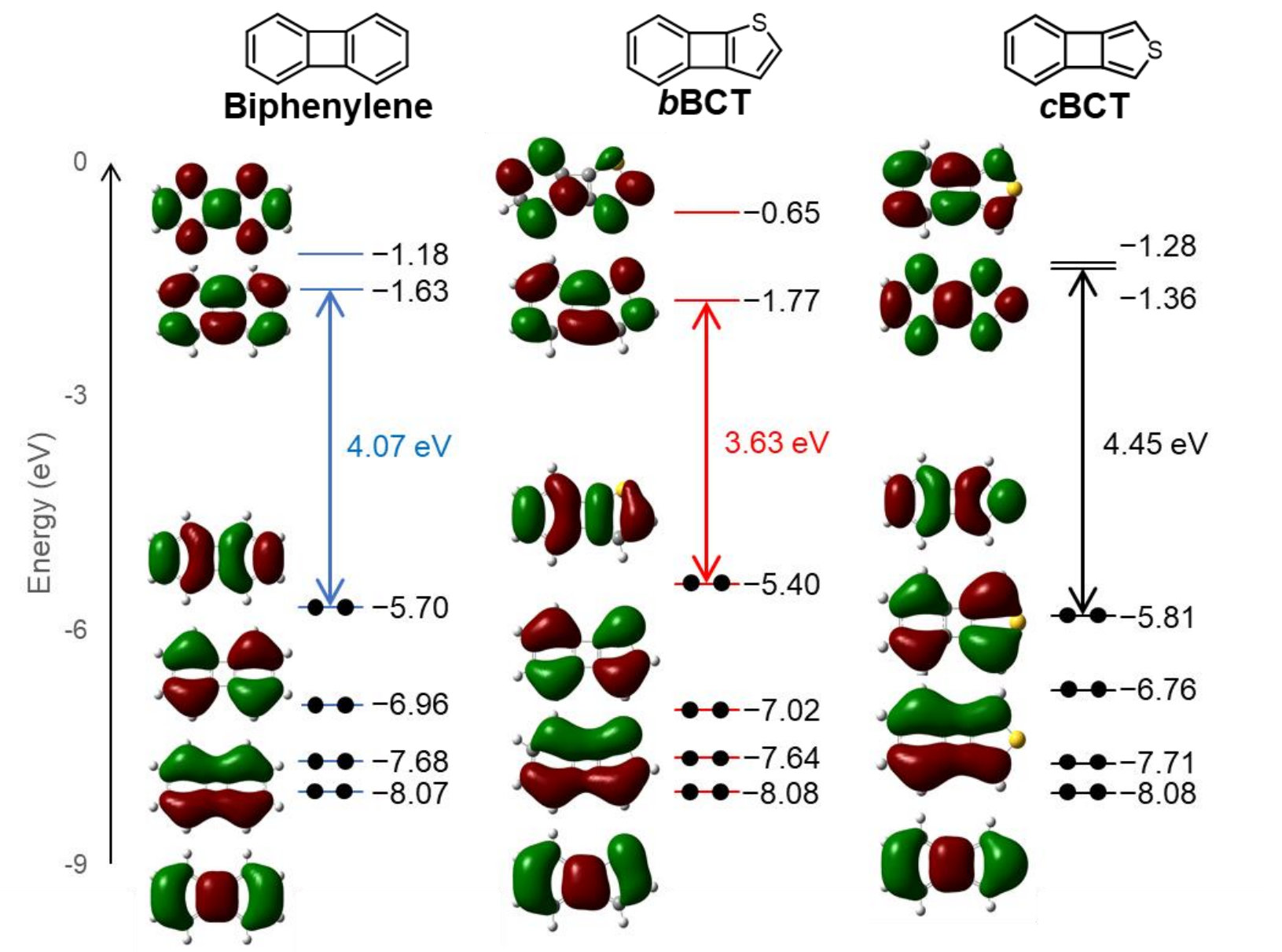

Figure S17. Molecular orbitals of biphenylene, $b \mathrm{BCT}$, and $c \mathrm{BCT}$. Black dots represent occupied electrons. 


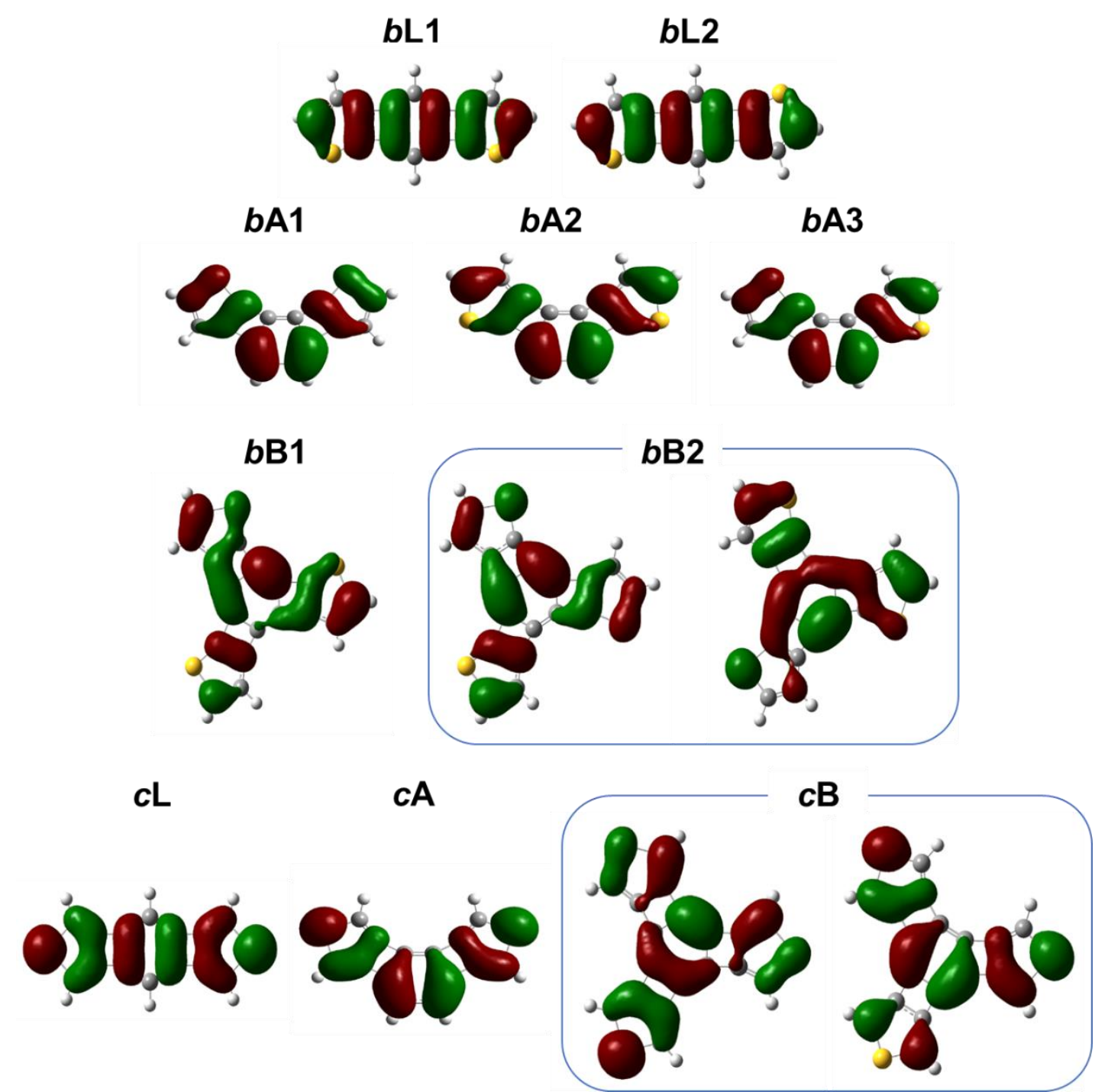

Figure S18. The HOMO distributions of the BCT homologues. The HOMOs of $b \mathrm{~B} 2$ and $c \mathrm{~B}$ are degenerate. 


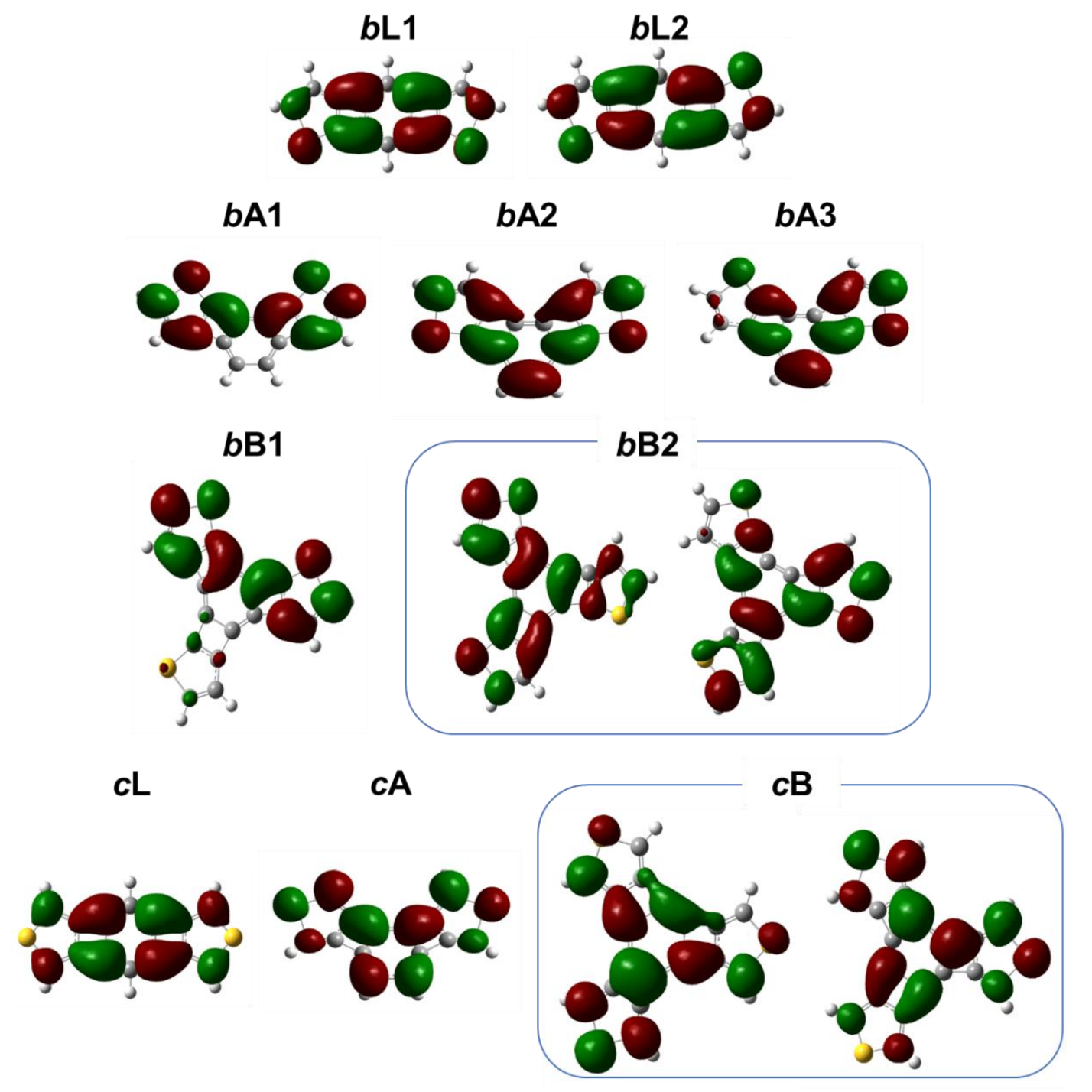

Figure S19. The LUMO distributions of the BCT homologues. The LUMOs of $b \mathrm{~B} 2$ and $c \mathrm{~B}$ are degenerate.

\section{References}

S1. Gershoni-Poranne, R.; Stanger, A. The NICS- $X Y$-Scan: Identification of Local and Global Ring Currents in Multi-Ring Systems. Chem.-Eur. J. 2014, 20, 5673-5688.

S2. GIMIC program is available free of charge from https://github.com/qmcurrents/gimic.

S3. Schäfer, A.; Horn, H.; Ahlrichs, R. Fully Optimized Contracted Gaussian Basis Sets for Atoms Li to Kr. J. Chem. Phys. 1992, 97, 2571-2577.

S4. Weigend, F.; Ahlrichs, R. Balanced Basis Sets of Split Valence, Triple Zeta Valence and Quadruple Zeta Valence Quality for H to Rn: Design and Assessment of Accuracy. Phys. Chem. Chem. Phys. 2005, 7, 32973305.

S5. Rauhalahti, M.; Taubert, S.; Sundholm, D.; Liégeois, V. Calculations of Current Densities for Neutral and Doubly Charged Persubstituted Benzenes using Effective Core Potentials. Phys. Chem. Chem. Phys. 2017, 19, $7124-7131$. 
17. Cartesian coordinates for all optimized geometries

\section{Biphenylene}

$\begin{array}{cccc}\text { Symbol } & \mathrm{X} & \mathrm{Y} & \mathrm{Z} \\ \mathrm{C} & 0.000000 & 1.442752 & 1.914275 \\ \mathrm{C} & 0.000000 & 0.710982 & 0.754458 \\ \mathrm{C} & 0.000000 & -0.710982 & 0.754458 \\ \mathrm{C} & 0.000000 & -1.442752 & 1.914275 \\ \mathrm{C} & 0.000000 & -0.694065 & 3.119710 \\ \mathrm{C} & 0.000000 & 0.694065 & 3.119710 \\ \mathrm{H} & 0.000000 & 2.527413 & 1.935658 \\ \mathrm{H} & 0.000000 & -2.527413 & 1.935658 \\ \mathrm{H} & 0.000000 & -1.221990 & 4.067998 \\ \mathrm{H} & 0.000000 & 1.221990 & 4.067998 \\ \mathrm{C} & 0.000000 & -0.710982 & -0.754458 \\ \mathrm{C} & 0.000000 & -1.442752 & -1.914275 \\ \mathrm{C} & 0.000000 & 0.710982 & -0.754458 \\ \mathrm{C} & 0.000000 & -0.694065 & -3.119710 \\ \mathrm{H} & 0.000000 & -2.527413 & -1.935658 \\ \mathrm{C} & 0.000000 & 1.442752 & -1.914275 \\ \mathrm{C} & 0.000000 & 0.694065 & -3.119710 \\ \mathrm{H} & 0.000000 & -1.221990 & -4.067998 \\ \mathrm{H} & 0.000000 & 2.527413 & -1.935658 \\ \mathrm{H} & 0.000000 & 1.221990 & -4.067998\end{array}$

Zero-point correction $=0.157577$ (Hartree/Particle)

Thermal correction to energy $=0.165731$

Thermal correction to enthalpy $=0.166675$

Thermal correction to Gibbs free energy $=0.125660$

Sum of electronic and zero-point energies $=-461.970735$

Sum of electronic and thermal energies $=-461.962581$

Sum of electronic and thermal enthalpies $=-461.961636$

Sum of electronic and thermal free energies $=-462.002651$ 


\section{$b \mathrm{BCT}$}

$\begin{array}{cccc}\text { Symbol } & \mathrm{X} & \mathrm{Y} & \mathrm{Z} \\ \mathrm{C} & -0.063603 & -2.479525 & 0.000000 \\ \mathrm{C} & -0.190506 & -1.123182 & 0.000000 \\ \mathrm{C} & 0.946667 & -0.256412 & 0.000000 \\ \mathrm{C} & 2.227443 & -0.719875 & 0.000000 \\ \mathrm{C} & 2.369985 & -2.142986 & 0.000000 \\ \mathrm{C} & 1.275989 & -2.983080 & 0.000000 \\ \mathrm{H} & -0.909853 & -3.157998 & 0.000000 \\ \mathrm{H} & 3.098468 & -0.073839 & 0.000000 \\ \mathrm{H} & 3.368072 & -2.568748 & 0.000000 \\ \mathrm{H} & 1.431015 & -4.057122 & 0.000000 \\ \mathrm{C} & 0.000000 & 0.918862 & 0.000000 \\ \mathrm{C} & -1.104384 & 0.093975 & 0.000000 \\ \mathrm{~S} & -0.425592 & 2.577239 & 0.000000 \\ \mathrm{C} & -2.337991 & 0.777040 & 0.000000 \\ \mathrm{C} & -2.122207 & 2.140863 & 0.000000 \\ \mathrm{H} & -3.327033 & 0.337465 & 0.000000 \\ \mathrm{H} & -2.859540 & 2.930341 & 0.000000\end{array}$

Zero-point correction $=0.123804($ Hartree/Particle $)$

Thermal correction to energy $=0.131871$

Thermal correction to enthalpy $=0.132815$

Thermal correction to Gibbs free energy $=0.090137$

Sum of electronic and zero-point energies $=-\mathbf{7 8 2 . 7 4 7 5 3 4}$

Sum of electronic and thermal energies $=-782.739467$

Sum of electronic and thermal enthalpies $=-782.738523$

Sum of electronic and thermal free energies $=-782.781200$ 


\section{$c \mathrm{BCT}$}

$\begin{array}{cccc}\text { Symbol } & \mathrm{X} & \mathrm{Y} & \mathrm{Z} \\ \mathrm{C} & 0.000000 & 1.444406 & -2.002306 \\ \mathrm{C} & 0.000000 & 0.711576 & -0.838963 \\ \mathrm{C} & 0.000000 & -0.711576 & -0.838963 \\ \mathrm{C} & 0.000000 & -1.444406 & -2.002306 \\ \mathrm{C} & 0.000000 & -0.696119 & -3.201969 \\ \mathrm{C} & 0.000000 & 0.696119 & -3.201969 \\ \mathrm{H} & 0.000000 & 2.528826 & -2.022323 \\ \mathrm{H} & 0.000000 & -2.528826 & -2.022323 \\ \mathrm{H} & 0.000000 & -1.222000 & -4.151330 \\ \mathrm{H} & 0.000000 & 1.222000 & -4.151330 \\ \mathrm{C} & 0.000000 & -0.722725 & 0.663210 \\ \mathrm{C} & 0.000000 & -1.281775 & 1.891260 \\ \mathrm{C} & 0.000000 & 0.722725 & 0.663210 \\ \mathrm{~S} & 0.000000 & 0.000000 & 3.111709 \\ \mathrm{H} & 0.000000 & -2.313177 & 2.212591 \\ \mathrm{C} & 0.000000 & 1.281775 & 1.891260 \\ \mathrm{H} & 0.000000 & 2.313177 & 2.212591\end{array}$

Zero-point correction $=0.124263($ Hartree/Particle $)$

Thermal correction to energy $=0.132116$

Thermal correction to enthalpy $=0.133060$

Thermal correction to Gibbs free energy $=0.091832$

Sum of electronic and zero-point energies $=-\mathbf{7 8 2 . 7 6 2 4 7 6}$

Sum of electronic and thermal energies $=-782.754623$

Sum of electronic and thermal enthalpies $=-782.753679$

Sum of electronic and thermal free energies $=-782.794906$ 


\section{$b \mathrm{~L} 1$}

$\begin{array}{cccc}\text { Symbol } & \mathrm{X} & \mathrm{Y} & \mathrm{Z} \\ \mathrm{C} & 1.325161 & -0.061456 & 0.000000 \\ \mathrm{C} & 0.545203 & -0.058651 & 1.152245 \\ \mathrm{C} & -0.866802 & -0.051056 & 1.157161 \\ \mathrm{C} & -1.641352 & -0.044117 & 0.000000 \\ \mathrm{C} & -0.866802 & -0.051056 & -1.157161 \\ \mathrm{C} & 0.545203 & -0.058651 & -1.152245 \\ \mathrm{H} & 2.408752 & -0.061626 & 0.000000 \\ \mathrm{H} & -2.725129 & -0.031243 & 0.000000 \\ \mathrm{C} & -0.858050 & -0.047827 & 2.690020 \\ \mathrm{C} & 0.518546 & -0.067454 & 2.669965 \\ \mathrm{C} & -1.418298 & 0.044731 & 3.976543 \\ \mathrm{~S} & 1.191192 & 0.042372 & 4.236490 \\ \mathrm{C} & -0.414859 & 0.094136 & 4.929492 \\ \mathrm{H} & -2.470418 & 0.071460 & 4.229499 \\ \mathrm{H} & -0.516347 & 0.130461 & 6.004027 \\ \mathrm{C} & -0.858050 & -0.047827 & -2.690020 \\ \mathrm{C} & 0.518546 & -0.067454 & -2.669965 \\ \mathrm{C} & -1.418298 & 0.044731 & -3.976543 \\ \mathrm{~S} & 1.191192 & 0.042372 & -4.236490 \\ \mathrm{C} & -0.414859 & 0.094136 & -4.929492 \\ \mathrm{H} & -2.470418 & 0.071460 & -4.229499 \\ \mathrm{H} & -0.516347 & 0.130461 & -6.004027\end{array}$

Zero-point correction $=0.146752($ Hartree/Particle $)$

Thermal correction to energy $=0.158967$

Thermal correction to enthalpy $=0.159912$

Thermal correction to Gibbs free energy $=0.106264$

Sum of electronic and zero-point energies $=-1333.289065$

Sum of electronic and thermal energies $=-1333.276849$

Sum of electronic and thermal enthalpies $=-1333.275905$

Sum of electronic and thermal free energies $=-1333.329553$ 


\section{bL2}

$\begin{array}{cccc}\text { Symbol } & \mathrm{X} & \mathrm{Y} & \mathrm{Z} \\ \mathrm{C} & -1.233684 & 0.823470 & 0.000000 \\ \mathrm{C} & 0.056781 & 1.347995 & 0.000000 \\ \mathrm{C} & 1.233684 & 0.567420 & 0.000000 \\ \mathrm{C} & 1.233684 & -0.823470 & 0.000000 \\ \mathrm{C} & -0.056781 & -1.347995 & 0.000000 \\ \mathrm{C} & -1.233684 & -0.567420 & 0.000000 \\ \mathrm{H} & -2.132764 & 1.428533 & 0.000000 \\ \mathrm{H} & 2.132764 & -1.428533 & 0.000000 \\ \mathrm{C} & 2.077417 & 1.848526 & 0.000000 \\ \mathrm{C} & 0.920569 & 2.594706 & 0.000000 \\ \mathrm{C} & 3.259016 & 2.610234 & 0.000000 \\ \mathrm{~S} & 1.231957 & 4.274514 & 0.000000 \\ \mathrm{C} & 2.953430 & 3.961189 & 0.000000 \\ \mathrm{H} & 4.275427 & 2.238044 & 0.000000 \\ \mathrm{H} & 3.634318 & 4.799352 & 0.000000 \\ \mathrm{C} & -2.077417 & -1.848526 & 0.000000 \\ \mathrm{C} & -0.920569 & -2.594706 & 0.000000 \\ \mathrm{C} & -3.259016 & -2.610234 & 0.000000 \\ \mathrm{~S} & -1.231957 & -4.274514 & 0.000000 \\ \mathrm{C} & -2.953430 & -3.961189 & 0.000000 \\ \mathrm{H} & -4.275427 & -2.238044 & 0.000000 \\ \mathrm{H} & -3.634318 & -4.799352 & 0.000000\end{array}$

Zero-point correction $=0.146588($ Hartree/Particle $)$

Thermal correction to energy $=0.158931$

Thermal correction to enthalpy $=0.159875$

Thermal correction to Gibbs free energy $=0.104810$

Sum of electronic and zero-point energies $=-1333.289249$

Sum of electronic and thermal energies $=-1333.276907$

Sum of electronic and thermal enthalpies $=-1333.275963$

Sum of electronic and thermal free energies $=-1333.331028$ 
bA1

$\begin{array}{cccc}\text { Symbol } & \mathrm{X} & \mathrm{Y} & \mathrm{Z} \\ \mathrm{C} & 0.000000 & 0.669233 & 0.139713 \\ \mathrm{C} & 0.000000 & -0.669233 & 0.139713 \\ \mathrm{C} & 0.000000 & -1.367528 & 1.449308 \\ \mathrm{C} & 0.000000 & -0.734082 & 2.640922 \\ \mathrm{C} & 0.000000 & 0.734082 & 2.640922 \\ \mathrm{C} & 0.000000 & 1.367528 & 1.449308 \\ \mathrm{H} & 0.000000 & -1.266546 & 3.585852 \\ \mathrm{H} & 0.000000 & 1.266546 & 3.585852 \\ \mathrm{C} & 0.000000 & -2.668141 & 0.708335 \\ \mathrm{C} & 0.000000 & -2.002140 & -0.507496 \\ \mathrm{C} & 0.000000 & -4.077637 & 0.590363 \\ \mathrm{~S} & 0.000000 & -3.077852 & -1.845774 \\ \mathrm{C} & 0.000000 & -4.440165 & -0.737833 \\ \mathrm{H} & 0.000000 & -4.798480 & 1.397676 \\ \mathrm{H} & 0.000000 & -5.438664 & -1.151021 \\ \mathrm{C} & 0.000000 & 2.668141 & 0.708335 \\ \mathrm{C} & 0.000000 & 2.002140 & -0.507496 \\ \mathrm{C} & 0.000000 & 4.077637 & 0.590363 \\ \mathrm{~S} & 0.000000 & 3.077852 & -1.845774 \\ \mathrm{C} & 0.000000 & 4.440165 & -0.737833 \\ \mathrm{H} & 0.000000 & 4.798480 & 1.397676 \\ \mathrm{H} & 0.000000 & 5.438664 & -1.151021\end{array}$

Zero-point correction $=0.147711($ Hartree/Particle $)$

Thermal correction to energy $=0.159531$

Thermal correction to enthalpy $=0.160475$

Thermal correction to Gibbs free energy $=0.109300$

Sum of electronic and zero-point energies $=-1333.306699$

Sum of electronic and thermal energies $=-1333.294879$

Sum of electronic and thermal enthalpies $=-1333.293935$

Sum of electronic and thermal free energies $=-1333.345110$ 
bA2

$\begin{array}{cccc}\text { Symbol } & \mathrm{X} & \mathrm{Y} & \mathrm{Z} \\ \mathrm{C} & 0.000000 & 1.358360 & 1.163675 \\ \mathrm{C} & 0.000000 & 0.669003 & -0.150838 \\ \mathrm{C} & 0.000000 & -0.669003 & -0.150838 \\ \mathrm{C} & 0.000000 & -1.358360 & 1.163675 \\ \mathrm{C} & 0.000000 & -0.731993 & 2.360980 \\ \mathrm{C} & 0.000000 & 0.731993 & 2.360980 \\ \mathrm{H} & 0.000000 & -1.267539 & 3.303907 \\ \mathrm{H} & 0.000000 & 1.267539 & 3.303907 \\ \mathrm{C} & 0.000000 & -2.638739 & 0.415430 \\ \mathrm{C} & 0.000000 & -2.007617 & -0.818830 \\ \mathrm{~S} & 0.000000 & -4.350900 & 0.270165 \\ \mathrm{C} & 0.000000 & -2.891538 & -1.921445 \\ \mathrm{C} & 0.000000 & -4.195708 & -1.479072 \\ \mathrm{H} & 0.000000 & -2.624572 & -2.970266 \\ \mathrm{H} & 0.000000 & -5.096651 & -2.075680 \\ \mathrm{C} & 0.000000 & 2.638739 & 0.415430 \\ \mathrm{C} & 0.000000 & 2.007617 & -0.818830 \\ \mathrm{~S} & 0.000000 & 4.350900 & 0.270165 \\ \mathrm{C} & 0.000000 & 2.891538 & -1.921445 \\ \mathrm{C} & 0.000000 & 4.195708 & -1.479072 \\ \mathrm{H} & 0.000000 & 2.624572 & -2.970266 \\ \mathrm{H} & 0.000000 & 5.096651 & -2.075680\end{array}$

Zero-point correction= $0.147571($ Hartree/Particle $)$

Thermal correction to energy $=0.159383$

Thermal correction to enthalpy $=0.160327$

Thermal correction to Gibbs free energy $=0.109265$

Sum of electronic and zero-point energies $=-1333.307547$

Sum of electronic and thermal energies $=-1333.295735$

Sum of electronic and thermal enthalpies $=-1333.294791$

Sum of electronic and thermal free energies $=-1333.345853$ 
bA3

\begin{tabular}{cccc} 
Symbol & $\mathrm{X}$ & $\mathrm{Y}$ & $\mathrm{Z}$ \\
$\mathrm{C}$ & 0.000000 & 0.597206 & 0.000000 \\
$\mathrm{C}$ & -0.013238 & -0.740915 & 0.000000 \\
$\mathrm{C}$ & 1.284497 & -1.461438 & 0.000000 \\
$\mathrm{C}$ & 2.487800 & -0.848465 & 0.000000 \\
$\mathrm{C}$ & 2.511183 & 0.617450 & 0.000000 \\
$\mathrm{C}$ & 1.325782 & 1.264101 & 0.000000 \\
$\mathrm{H}$ & 3.423830 & -1.396269 & 0.000000 \\
$\mathrm{H}$ & 3.462794 & 1.137563 & 0.000000 \\
$\mathrm{C}$ & 0.524472 & -2.749670 & 0.000000 \\
$\mathrm{C}$ & -0.681050 & -2.065985 & 0.000000 \\
$\mathrm{C}$ & 0.386068 & -4.157869 & 0.000000 \\
$\mathrm{~S}$ & -2.034480 & -3.122059 & 0.000000 \\
$\mathrm{C}$ & -0.946750 & -4.501230 & 0.000000 \\
$\mathrm{H}$ & 1.183020 & -4.890169 & 0.000000 \\
$\mathrm{H}$ & -1.374631 & -5.493506 & 0.000000 \\
$\mathrm{C}$ & -0.647163 & 1.943822 & 0.000000 \\
$\mathrm{C}$ & 0.596470 & 2.556786 & 0.000000 \\
$\mathrm{C}$ & -1.737238 & 2.843572 & 0.000000 \\
$\mathrm{~S}$ & 0.476001 & 4.270262 & 0.000000 \\
$\mathrm{C}$ & -1.275930 & 4.140813 & 0.000000 \\
$\mathrm{H}$ & -2.789724 & 2.591554 & 0.000000 \\
$\mathrm{H}$ & -1.859065 & 5.050508 & 0.000000 \\
\hline & & &
\end{tabular}

Zero-point correction $=0.147643($ Hartree/Particle $)$

Thermal correction to energy $=0.159460$

Thermal correction to enthalpy $=0.160404$

Thermal correction to Gibbs free energy $=0.108626$

Sum of electronic and zero-point energies $=-1333.307127$

Sum of electronic and thermal energies $=-1333.295310$

Sum of electronic and thermal enthalpies $=-1333.294366$

Sum of electronic and thermal free energies $=-1333.346144$ 
bB1

$\begin{array}{cccc}\text { Symbol } & \mathrm{X} & \mathrm{Y} & \mathrm{Z} \\ \mathrm{C} & 0.000000 & 1.304927 & 0.000000 \\ \mathrm{C} & 1.181522 & 0.682441 & 0.000000 \\ \mathrm{C} & 1.245302 & -0.836238 & 0.000000 \\ \mathrm{C} & 0.116659 & -1.547511 & 0.000000 \\ \mathrm{C} & -1.226647 & -0.834423 & 0.000000 \\ \mathrm{C} & -1.287556 & 0.498891 & 0.000000 \\ \mathrm{C} & 2.723349 & -0.720983 & 0.000000 \\ \mathrm{C} & 2.649264 & 0.667308 & 0.000000 \\ \mathrm{C} & 4.046165 & -1.226116 & 0.000000 \\ \mathrm{~S} & 4.203689 & 1.406131 & 0.000000 \\ \mathrm{C} & 4.946761 & -0.187278 & 0.000000 \\ \mathrm{H} & 4.345432 & -2.266165 & 0.000000 \\ \mathrm{H} & 6.025731 & -0.249488 & 0.000000 \\ \mathrm{C} & -2.030357 & 1.779932 & 0.000000 \\ \mathrm{C} & -0.844529 & 2.506496 & 0.000000 \\ \mathrm{C} & -3.197060 & 2.582477 & 0.000000 \\ \mathrm{~S} & -1.118006 & 4.205052 & 0.000000 \\ \mathrm{C} & -2.852330 & 3.913186 & 0.000000 \\ \mathrm{H} & -4.223190 & 2.238605 & 0.000000 \\ \mathrm{H} & -3.515365 & 4.766640 & 0.000000 \\ \mathrm{C} & -0.623107 & -2.831419 & 0.000000 \\ \mathrm{C} & -1.844231 & -2.168091 & 0.000000 \\ \mathrm{C} & -0.735155 & -4.243556 & 0.000000 \\ \mathrm{~S} & -3.178932 & -3.254467 & 0.000000 \\ \mathrm{C} & -2.059591 & -4.610853 & 0.000000 \\ \mathrm{H} & 0.075698 & -4.960373 & 0.000000 \\ \mathrm{H} & -2.467093 & -5.611832 & 0.000000 \\ & & & \\ \mathrm{H} & & & \end{array}$

Zero-point correction $=0.171131($ Hartree/Particle $)$

Thermal correction to energy $=0.187018$

Thermal correction to enthalpy $=0.187962$

Thermal correction to Gibbs free energy $=0.126655$

Sum of electronic and zero-point energies $=-1883.877232$

Sum of electronic and thermal energies $=-1883.861346$

Sum of electronic and thermal enthalpies $=-1883.860402$

Sum of electronic and thermal free energies $=-1883.921708$ 
bB2

$\begin{array}{cccc}\text { Symbol } & \mathrm{X} & \mathrm{Y} & \mathrm{Z} \\ \mathrm{C} & 1.183362 & 0.806953 & 0.000000 \\ \mathrm{C} & 0.000000 & 1.424327 & 0.000000 \\ \mathrm{C} & -1.290523 & 0.621345 & 0.000000 \\ \mathrm{C} & -1.233503 & -0.712163 & 0.000000 \\ \mathrm{C} & 0.107161 & -1.428298 & 0.000000 \\ \mathrm{C} & 1.233503 & -0.712163 & 0.000000 \\ \mathrm{C} & -2.030909 & 1.902849 & 0.000000 \\ \mathrm{C} & -0.844847 & 2.627929 & 0.000000 \\ \mathrm{C} & -3.197549 & 2.706511 & 0.000000 \\ \mathrm{~S} & -1.117225 & 4.326519 & 0.000000 \\ \mathrm{C} & -2.852346 & 4.036640 & 0.000000 \\ \mathrm{H} & -4.223853 & 2.363095 & 0.000000 \\ \mathrm{H} & -3.514583 & 4.890695 & 0.000000 \\ \mathrm{C} & -0.632461 & -2.710243 & 0.000000 \\ \mathrm{C} & -1.853430 & -2.045623 & 0.000000 \\ \mathrm{C} & -0.745133 & -4.122414 & 0.000000 \\ \mathrm{~S} & -3.188263 & -3.130805 & 0.000000 \\ \mathrm{C} & -2.069660 & -4.488524 & 0.000000 \\ \mathrm{H} & 0.065426 & -4.839511 & 0.000000 \\ \mathrm{H} & -2.478175 & -5.489066 & 0.000000 \\ \mathrm{C} & 2.663370 & 0.807394 & 0.000000 \\ \mathrm{C} & 2.698276 & -0.582306 & 0.000000 \\ \mathrm{C} & 3.942682 & 1.415903 & 0.000000 \\ \mathrm{~S} & 4.305488 & -1.195714 & 0.000000 \\ \mathrm{C} & 4.922006 & 0.451884 & 0.000000 \\ \mathrm{H} & 4.158427 & 2.476416 & 0.000000 \\ \mathrm{H} & 5.992758 & 0.598371 & 0.000000\end{array}$

Zero-point correction $=0.171036($ Hartree/Particle $)$

Thermal correction to energy $=0.186924$

Thermal correction to enthalpy $=0.187868$

Thermal correction to Gibbs free energy $=0.127643$

Sum of electronic and zero-point energies $=-1883.877331$

Sum of electronic and thermal energies $=-1883.861444$

Sum of electronic and thermal enthalpies $=-1883.860500$

Sum of electronic and thermal free energies $=-1883.920724$ 
$c \mathbf{L}$

$\begin{array}{cccc}\text { Symbol } & \mathrm{X} & \mathrm{Y} & \mathrm{Z} \\ \mathrm{C} & 0.000000 & 0.000000 & 1.489557 \\ \mathrm{C} & 0.000000 & 1.154902 & 0.712377 \\ \mathrm{C} & 0.000000 & 1.154902 & -0.712377 \\ \mathrm{C} & 0.000000 & 0.000000 & -1.489557 \\ \mathrm{C} & 0.000000 & -1.154902 & -0.712377 \\ \mathrm{C} & 0.000000 & -1.154902 & 0.712377 \\ \mathrm{H} & 0.000000 & 0.000000 & 2.573377 \\ \mathrm{H} & 0.000000 & 0.000000 & -2.573377 \\ \mathrm{C} & 0.000000 & 2.654286 & -0.722607 \\ \mathrm{C} & 0.000000 & 3.881264 & -1.282243 \\ \mathrm{C} & 0.000000 & 2.654286 & 0.722607 \\ \mathrm{~S} & 0.000000 & 5.105240 & 0.000000 \\ \mathrm{H} & 0.000000 & 4.201465 & -2.313978 \\ \mathrm{C} & 0.000000 & 3.881264 & 1.282243 \\ \mathrm{H} & 0.000000 & 4.201465 & 2.313978 \\ \mathrm{C} & 0.000000 & -2.654286 & -0.722607 \\ \mathrm{C} & 0.000000 & -3.881264 & -1.282243 \\ \mathrm{C} & 0.000000 & -2.654286 & 0.722607 \\ \mathrm{~S} & 0.000000 & -5.105240 & 0.000000 \\ \mathrm{H} & 0.000000 & -4.201465 & -2.313978 \\ \mathrm{C} & 0.000000 & -3.881264 & 1.282243 \\ \mathrm{H} & 0.000000 & -4.201465 & 2.313978\end{array}$

Zero-point correction $=0.148024($ Hartree/Particle $)$

Thermal correction to energy $=0.159605$

Thermal correction to enthalpy $=0.160549$

Thermal correction to Gibbs free energy $=0.110856$

Sum of electronic and zero-point energies $=-1333.327534$

Sum of electronic and thermal energies $=-1333.315953$

Sum of electronic and thermal enthalpies $=-1333.315009$

Sum of electronic and thermal free energies $=-1333.364702$ 
$c \mathbf{A}$

$\begin{array}{cccc}\text { Symbol } & \mathrm{X} & \mathrm{Y} & \mathrm{Z} \\ \mathrm{C} & 0.000000 & 0.679164 & 0.059958 \\ \mathrm{C} & 0.000000 & -0.679164 & 0.059958 \\ \mathrm{C} & 0.000000 & -1.357069 & 1.340310 \\ \mathrm{C} & 0.000000 & -0.717492 & 2.552049 \\ \mathrm{C} & 0.000000 & 0.717492 & 2.552049 \\ \mathrm{C} & 0.000000 & 1.357069 & 1.340310 \\ \mathrm{H} & 0.000000 & -1.258471 & 3.492033 \\ \mathrm{H} & 0.000000 & 1.258471 & 3.492033 \\ \mathrm{C} & 0.000000 & -2.676768 & 0.631016 \\ \mathrm{C} & 0.000000 & -4.025627 & 0.541817 \\ \mathrm{C} & 0.000000 & -1.996733 & -0.644449 \\ \mathrm{~S} & 0.000000 & -4.492361 & -1.161678 \\ \mathrm{H} & 0.000000 & -4.796881 & 1.298155 \\ \mathrm{C} & 0.000000 & -2.817125 & -1.718103 \\ \mathrm{H} & 0.000000 & -2.613603 & -2.778916 \\ \mathrm{C} & 0.000000 & 2.676768 & 0.631016 \\ \mathrm{C} & 0.000000 & 4.025627 & 0.541817 \\ \mathrm{C} & 0.000000 & 1.996733 & -0.644449 \\ \mathrm{~S} & 0.000000 & 4.492361 & -1.161678 \\ \mathrm{H} & 0.000000 & 4.796881 & 1.298155 \\ \mathrm{C} & 0.000000 & 2.817125 & -1.718103 \\ \mathrm{H} & 0.000000 & 2.613603 & -2.778916\end{array}$

Zero-point correction $=0.148220$ (Hartree/Particle $)$

Thermal correction to energy $=0.159739$

Thermal correction to enthalpy $=0.160684$

Thermal correction to Gibbs free energy $=0.110446$

Sum of electronic and zero-point energies $=-1333.327184$

Sum of electronic and thermal energies $=-1333.315665$

Sum of electronic and thermal enthalpies $=-1333.314721$

Sum of electronic and thermal free energies $=-1333.364959$ 
$c \mathbf{B}$

$\begin{array}{cccc}\text { Symbol } & \mathrm{X} & \mathrm{Y} & \mathrm{Z} \\ \mathrm{C} & 0.676369 & 1.242730 & 0.000000 \\ \mathrm{C} & -0.676369 & 1.242730 & 0.000000 \\ \mathrm{C} & -1.414420 & -0.035612 & 0.000000 \\ \mathrm{C} & -0.738051 & -1.207118 & 0.000000 \\ \mathrm{C} & 0.738051 & -1.207118 & 0.000000 \\ \mathrm{C} & 1.414420 & -0.035612 & 0.000000 \\ \mathrm{C} & -2.696889 & 0.722583 & 0.000000 \\ \mathrm{C} & -4.044114 & 0.855512 & 0.000000 \\ \mathrm{C} & -1.974220 & 1.974283 & 0.000000 \\ \mathrm{~S} & -4.451017 & 2.569796 & 0.000000 \\ \mathrm{H} & -4.839238 & 0.124510 & 0.000000 \\ \mathrm{C} & -2.762952 & 3.074550 & 0.000000 \\ \mathrm{H} & -2.527448 & 4.128648 & 0.000000 \\ \mathrm{C} & -0.722670 & -2.696866 & 0.000000 \\ \mathrm{C} & -1.281162 & -3.930061 & 0.000000 \\ \mathrm{C} & 0.722670 & -2.696866 & 0.000000 \\ \mathrm{~S} & 0.000000 & -5.139592 & 0.000000 \\ \mathrm{H} & -2.311790 & -4.253159 & 0.000000 \\ \mathrm{C} & 1.281162 & -3.930061 & 0.000000 \\ \mathrm{H} & 2.311790 & -4.253159 & 0.000000 \\ \mathrm{C} & 2.696889 & 0.722583 & 0.000000 \\ \mathrm{C} & 4.044114 & 0.855512 & 0.000000 \\ \mathrm{C} & 1.974220 & 1.974283 & 0.000000 \\ \mathrm{~S} & 4.451017 & 2.569796 & 0.000000 \\ \mathrm{H} & 4.839238 & 0.124510 & 0.000000 \\ \mathrm{C} & 2.762952 & 3.074550 & 0.000000 \\ \mathrm{H} & 2.527448 & 4.128648 & 0.000000\end{array}$

Zero-point correction $=0.171756($ Hartree/Particle $)$

Thermal correction to energy $=0.187173$

Thermal correction to enthalpy $=0.188117$

Thermal correction to Gibbs free energy $=0.129783$

Sum of electronic and zero-point energies $=-1883.895868$

Sum of electronic and thermal energies $=-1883.880451$

Sum of electronic and thermal enthalpies $=-1883.879507$

Sum of electronic and thermal free energies $=-1883.937841$ 
$b c \mathbf{L}$

$\begin{array}{cccc}\text { Symbol } & \mathrm{X} & \mathrm{Y} & \mathrm{Z} \\ \mathrm{C} & 0.000000 & 1.277912 & 0.000000 \\ \mathrm{C} & 1.256032 & 0.641849 & 0.000000 \\ \mathrm{C} & 1.137699 & -0.729921 & 0.000000 \\ \mathrm{C} & -0.107986 & -1.436511 & 0.000000 \\ \mathrm{C} & -1.337655 & -0.817905 & 0.000000 \\ \mathrm{C} & -1.227811 & 0.587034 & 0.000000 \\ \mathrm{H} & 2.201110 & 1.172069 & 0.000000 \\ \mathrm{H} & -2.283499 & -1.347027 & 0.000000 \\ \mathrm{C} & 0.654807 & -2.754812 & 0.000000 \\ \mathrm{C} & 0.798836 & -4.155718 & 0.000000 \\ \mathrm{C} & 1.846130 & -2.061853 & 0.000000 \\ \mathrm{C} & 2.139537 & -4.492109 & 0.000000 \\ \mathrm{H} & 0.006864 & -4.893317 & 0.000000 \\ \mathrm{~S} & 3.203853 & -3.101379 & 0.000000 \\ \mathrm{H} & 2.577629 & -5.479400 & 0.000000 \\ \mathrm{C} & -1.980476 & 1.885045 & 0.000000 \\ \mathrm{C} & -0.719727 & 2.595314 & 0.000000 \\ \mathrm{C} & -3.069180 & 2.677630 & 0.000000 \\ \mathrm{C} & -0.832921 & 3.936867 & 0.000000 \\ \mathrm{~S} & -2.555765 & 4.380161 & 0.000000 \\ \mathrm{H} & -4.125045 & 2.448825 & 0.000000 \\ \mathrm{H} & -0.090189 & 4.721408 & 0.000000\end{array}$

Zero-point correction $=0.147559($ Hartree/Particle $)$

Thermal correction to Energy $=0.159400$

Thermal correction to Enthalpy $=0.160344$

Thermal correction to Gibbs Free Energy $=0.108318$

Sum of electronic and zero-point Energies $=-1333.310324$

Sum of electronic and thermal Energies $=-1333.298483$

Sum of electronic and thermal Enthalpies= -1333.297539

Sum of electronic and thermal Free Energies $=-1333.349565$ 
bcA1

$\begin{array}{cccc}\text { Symbol } & \mathrm{X} & \mathrm{Y} & \mathrm{Z} \\ \mathrm{C} & 1.613875 & -1.184827 & 0.000000 \\ \mathrm{C} & 0.229353 & -0.720824 & 0.000000 \\ \mathrm{C} & 0.000000 & 0.606635 & 0.000000 \\ \mathrm{C} & 1.164760 & 1.500515 & 0.000000 \\ \mathrm{C} & 2.455077 & 1.073124 & 0.000000 \\ \mathrm{C} & 2.692753 & -0.360027 & 0.000000 \\ \mathrm{H} & 3.296944 & 1.756803 & 0.000000 \\ \mathrm{H} & 3.710330 & -0.735381 & 0.000000 \\ \mathrm{C} & 0.240292 & 2.673388 & 0.000000 \\ \mathrm{C} & -0.904378 & 1.790181 & 0.000000 \\ \mathrm{C} & -0.075254 & 3.990343 & 0.000000 \\ \mathrm{C} & -2.101249 & 2.421889 & 0.000000 \\ \mathrm{~S} & -1.829441 & 4.162559 & 0.000000 \\ \mathrm{H} & 0.540551 & 4.877769 & 0.000000 \\ \mathrm{H} & -3.113636 & 2.045438 & 0.000000 \\ \mathrm{C} & 1.103084 & -2.606085 & 0.000000 \\ \mathrm{C} & 1.222021 & -4.013025 & 0.000000 \\ \mathrm{C} & -0.202062 & -2.150784 & 0.000000 \\ \mathrm{C} & -0.029644 & -4.591977 & 0.000000 \\ \mathrm{H} & 2.137731 & -4.589894 & 0.000000 \\ \mathrm{~S} & -1.342491 & -3.430133 & 0.000000 \\ \mathrm{H} & -0.272790 & -5.644708 & 0.000000\end{array}$

Zero-point correction $=0.147918($ Hartree/Particle $)$

Thermal correction to Energy= 0.159610

Thermal correction to Enthalpy $=0.160554$

Thermal correction to Gibbs Free Energy $=0.109064$

Sum of electronic and zero-point Energies $=-1333.315303$

Sum of electronic and thermal Energies $=-1333.303610$

Sum of electronic and thermal Enthalpies $=-1333.302666$

Sum of electronic and thermal Free Energies $=-1333.354156$ 


\section{bcA2}

$\begin{array}{cccc}\text { Symbol } & \mathrm{X} & \mathrm{Y} & \mathrm{Z} \\ \mathrm{C} & 1.167463 & 1.426263 & 0.000000 \\ \mathrm{C} & -0.083322 & 0.672717 & 0.000000 \\ \mathrm{C} & 0.000000 & -0.671833 & 0.000000 \\ \mathrm{C} & 1.336111 & -1.281881 & 0.000000 \\ \mathrm{C} & 2.498619 & -0.576307 & 0.000000 \\ \mathrm{C} & 2.407714 & 0.871950 & 0.000000 \\ \mathrm{H} & 3.472578 & -1.053200 & 0.000000 \\ \mathrm{H} & 3.312767 & 1.469335 & 0.000000 \\ \mathrm{C} & 0.700014 & -2.631947 & 0.000000 \\ \mathrm{C} & -0.614528 & -2.030386 & 0.000000 \\ \mathrm{C} & 0.690830 & -3.986514 & 0.000000 \\ \mathrm{C} & -1.637030 & -2.916621 & 0.000000 \\ \mathrm{~S} & -0.978200 & -4.551128 & 0.000000 \\ \mathrm{H} & 1.491731 & -4.711302 & 0.000000 \\ \mathrm{H} & -2.708410 & -2.779550 & 0.000000 \\ \mathrm{C} & -0.846210 & 1.971637 & 0.000000 \\ \mathrm{C} & -2.001633 & 2.782249 & 0.000000 \\ \mathrm{C} & 0.343177 & 2.676141 & 0.000000 \\ \mathrm{C} & -1.641852 & 4.113250 & 0.000000 \\ \mathrm{H} & -3.031378 & 2.449430 & 0.000000 \\ \mathrm{~S} & 0.093123 & 4.372190 & 0.000000 \\ \mathrm{H} & -2.292166 & 4.975989 & 0.000000\end{array}$

Zero-point correction $=0.147888($ Hartree/Particle $)$

Thermal correction to Energy= 0.159572

Thermal correction to Enthalpy $=0.160516$

Thermal correction to Gibbs Free Energy $=0.109102$

Sum of electronic and zero-point Energies $=-1333.315567$

Sum of electronic and thermal Energies $=-1333.303884$

Sum of electronic and thermal Enthalpies= -1333.302939

Sum of electronic and thermal Free Energies $=-1333.354353$ 


\section{Linear [3]phenylene}

$\begin{array}{cccc}\text { Symbol } & \mathrm{X} & \mathrm{Y} & \mathrm{Z} \\ \mathrm{C} & 0.000000 & 3.822015 & 1.443030 \\ \mathrm{C} & 0.000000 & 2.665054 & 0.711468 \\ \mathrm{C} & 0.000000 & 2.665054 & -0.711468 \\ \mathrm{C} & 0.000000 & 3.822015 & -1.443030 \\ \mathrm{C} & 0.000000 & 5.031311 & -0.692531 \\ \mathrm{C} & 0.000000 & 5.031311 & 0.692531 \\ \mathrm{H} & 0.000000 & 3.843692 & 2.527646 \\ \mathrm{H} & 0.000000 & 3.843692 & -2.527646 \\ \mathrm{H} & 0.000000 & 5.978843 & -1.221692 \\ \mathrm{H} & 0.000000 & 5.978843 & 1.221692 \\ \mathrm{C} & 0.000000 & 1.156190 & -0.708913 \\ \mathrm{C} & 0.000000 & 1.156190 & 0.708913 \\ \mathrm{C} & 0.000000 & 0.000000 & -1.485062 \\ \mathrm{C} & 0.000000 & 0.000000 & 1.485062 \\ \mathrm{C} & 0.000000 & -1.156190 & -0.708913 \\ \mathrm{H} & 0.000000 & 0.000000 & -2.569288 \\ \mathrm{C} & 0.000000 & -1.156190 & 0.708913 \\ \mathrm{H} & 0.000000 & 0.000000 & 2.569288 \\ \mathrm{C} & 0.000000 & -2.665054 & -0.711468 \\ \mathrm{C} & 0.000000 & -2.665054 & 0.711468 \\ \mathrm{C} & 0.000000 & -3.822015 & -1.443030 \\ \mathrm{C} & 0.000000 & -3.822015 & 1.443030 \\ \mathrm{C} & 0.000000 & -5.031311 & -0.692531 \\ \mathrm{H} & 0.000000 & -3.843692 & -2.527646 \\ \mathrm{C} & 0.000000 & -5.031311 & 0.692531 \\ \mathrm{H} & 0.000000 & -3.843692 & 2.527646 \\ \mathrm{H} & 0.000000 & -5.978843 & -1.221692 \\ \mathrm{H} & 0.000000 & -5.978843 & 1.221692 \\ & & & \end{array}$

Zero-point correction $=0.214590($ Hartree/Particle $)$

Thermal correction to energy $=0.226788$

Thermal correction to enthalpy $=0.227732$

Thermal correction to Gibbs free energy $=0.177113$

Sum of electronic and zero-point energies $=-691.742271$

Sum of electronic and thermal energies $=-691.730073$

Sum of electronic and thermal enthalpies $=-691.729129$

Sum of electronic and thermal free energies $=-691.779748$ 


\section{Angular [3]phenylene}

\begin{tabular}{|c|c|c|c|}
\hline Symbol & $\mathrm{X}$ & Y & $\mathrm{Z}$ \\
\hline $\mathrm{C}$ & 0.000000 & 4.045054 & 0.669872 \\
\hline $\mathrm{C}$ & 0.000000 & 2.672123 & 0.575497 \\
\hline $\mathrm{C}$ & 0.000000 & 2.002956 & -0.679921 \\
\hline $\mathrm{C}$ & 0.000000 & 2.682944 & -1.875254 \\
\hline $\mathrm{C}$ & 0.000000 & 4.093729 & -1.783428 \\
\hline $\mathrm{C}$ & 0.000000 & 4.750205 & -0.555278 \\
\hline $\mathrm{H}$ & 0.000000 & 4.576345 & 1.615703 \\
\hline $\mathrm{H}$ & 0.000000 & 2.188730 & -2.840899 \\
\hline $\mathrm{H}$ & 0.000000 & 4.682470 & -2.695152 \\
\hline $\mathrm{H}$ & 0.000000 & 5.835457 & -0.539341 \\
\hline $\mathrm{C}$ & 0.000000 & 0.675918 & 0.013550 \\
\hline $\mathrm{C}$ & 0.000000 & -0.675918 & 0.013550 \\
\hline $\mathrm{C}$ & 0.000000 & 1.358758 & 1.298943 \\
\hline $\mathrm{C}$ & 0.000000 & -1.358758 & 1.298943 \\
\hline $\mathrm{C}$ & 0.000000 & 0.723149 & 2.504780 \\
\hline $\mathrm{C}$ & 0.000000 & -0.723149 & 2.504780 \\
\hline $\mathrm{H}$ & 0.000000 & 1.260652 & 3.447121 \\
\hline $\mathrm{H}$ & 0.000000 & -1.260652 & 3.447121 \\
\hline $\mathrm{C}$ & 0.000000 & -2.672123 & 0.575497 \\
\hline $\mathrm{C}$ & 0.000000 & -4.045054 & 0.669872 \\
\hline $\mathrm{C}$ & 0.000000 & -2.002956 & -0.679921 \\
\hline $\mathrm{C}$ & 0.000000 & -4.750205 & -0.555278 \\
\hline $\mathrm{H}$ & 0.000000 & -4.576345 & 1.615703 \\
\hline $\mathrm{C}$ & 0.000000 & -2.682944 & -1.875254 \\
\hline $\mathrm{C}$ & 0.000000 & -4.093729 & -1.783428 \\
\hline $\mathrm{H}$ & 0.000000 & -5.835457 & -0.539341 \\
\hline $\mathrm{H}$ & 0.000000 & -2.188730 & -2.840899 \\
\hline $\mathrm{H}$ & 0.000000 & -4.682470 & -2.695152 \\
\hline
\end{tabular}

Zero-point correction $=0.215008($ Hartree/Particle $)$

Thermal correction to energy $=0.227120$

Thermal correction to enthalpy $=0.228065$

Thermal correction to Gibbs free energy $=0.176978$

Sum of electronic and zero-point energies $=-691.746394$

Sum of electronic and thermal energies $=-691.734282$

Sum of electronic and thermal enthalpies $=-691.733338$

Sum of electronic and thermal free energies $=-691.784424$ 


\section{Branched [4]phenylene}

\begin{tabular}{|c|c|c|c|}
\hline Symbol & $X$ & $\mathrm{Y}$ & Z \\
\hline $\mathrm{C}$ & 0.672578 & 1.248163 & 0.000000 \\
\hline $\mathrm{C}$ & -0.672578 & 1.248163 & 0.000000 \\
\hline $\mathrm{C}$ & -1.417230 & -0.041612 & 0.000000 \\
\hline $\mathrm{C}$ & -0.744652 & -1.206552 & 0.000000 \\
\hline $\mathrm{C}$ & 0.744652 & -1.206552 & 0.000000 \\
\hline $\mathrm{C}$ & 1.417230 & -0.041612 & 0.000000 \\
\hline $\mathrm{C}$ & -2.689079 & 0.730734 & 0.000000 \\
\hline $\mathrm{C}$ & -4.068017 & 0.681313 & 0.000000 \\
\hline $\mathrm{C}$ & -1.977374 & 1.963444 & 0.000000 \\
\hline $\mathrm{C}$ & -4.730472 & 1.924678 & 0.000000 \\
\hline $\mathrm{H}$ & -4.628175 & -0.247613 & 0.000000 \\
\hline $\mathrm{C}$ & -2.624043 & 3.182350 & 0.000000 \\
\hline $\mathrm{C}$ & -4.032056 & 3.134370 & 0.000000 \\
\hline $\mathrm{H}$ & -5.815612 & 1.945703 & 0.000000 \\
\hline $\mathrm{H}$ & -2.099648 & 4.131923 & 0.000000 \\
\hline $\mathrm{H}$ & -4.592834 & 4.063616 & 0.000000 \\
\hline $\mathrm{C}$ & -0.711705 & -2.694178 & 0.000000 \\
\hline $\mathrm{C}$ & -1.443974 & -3.863662 & 0.000000 \\
\hline $\mathrm{C}$ & 0.711705 & -2.694178 & 0.000000 \\
\hline $\mathrm{C}$ & -0.698416 & -5.059048 & 0.000000 \\
\hline $\mathrm{H}$ & -2.528527 & -3.884310 & 0.000000 \\
\hline $\mathrm{C}$ & 1.443974 & -3.863662 & 0.000000 \\
\hline $\mathrm{C}$ & 0.698416 & -5.059048 & 0.000000 \\
\hline $\mathrm{H}$ & -1.222778 & -6.009319 & 0.000000 \\
\hline $\mathrm{H}$ & 2.528527 & -3.884310 & 0.000000 \\
\hline $\mathrm{H}$ & 1.222778 & -6.009319 & 0.000000 \\
\hline $\mathrm{C}$ & 1.977374 & 1.963444 & 0.000000 \\
\hline $\mathrm{C}$ & 2.624043 & 3.182350 & 0.000000 \\
\hline $\mathrm{C}$ & 2.689079 & 0.730734 & 0.000000 \\
\hline $\mathrm{C}$ & 4.032056 & 3.134370 & 0.000000 \\
\hline $\mathrm{H}$ & 2.099648 & 4.131923 & 0.000000 \\
\hline $\mathrm{C}$ & 4.068017 & 0.681313 & 0.000000 \\
\hline $\mathrm{C}$ & 4.730472 & 1.924678 & 0.000000 \\
\hline $\mathrm{H}$ & 4.592834 & 4.063616 & 0.000000 \\
\hline $\mathrm{H}$ & 4.628175 & -0.247613 & 0.000000 \\
\hline $\mathrm{H}$ & 5.815612 & 1.945703 & 0.000000 \\
\hline
\end{tabular}


Zero-point correction $=0.271091$ (Hartree/Particle $)$

Thermal correction to energy $=0.287797$

Thermal correction to enthalpy $=0.288742$

Thermal correction to Gibbs free energy $=0.228208$

Sum of electronic and zero-point energies $=-921.529529$

Sum of electronic and thermal energies $=-921.512822$

Sum of electronic and thermal enthalpies $=-921.511878$

Sum of electronic and thermal free energies $=-921.572411$

\section{Benzene}

\begin{tabular}{lrrr} 
Symbol & \multicolumn{3}{c}{$\mathrm{Y}$} \\
$\mathrm{C}$ & $\mathrm{X}$ & \\
$\mathrm{C}$ & -1.2000000 & 1.394768 & 0.000000 \\
$\mathrm{C}$ & 1.207904 & 0.697384 & 0.000000 \\
$\mathrm{C}$ & -1.207904 & -0.697384 & 0.000000 \\
$\mathrm{H}$ & -2.147997 & 1.240146 & 0.000000 \\
$\mathrm{H}$ & 0.000000 & 2.480293 & 0.000000 \\
$\mathrm{C}$ & 1.207904 & -0.697384 & 0.000000 \\
$\mathrm{H}$ & 2.147997 & 1.240146 & 0.000000 \\
$\mathrm{C}$ & 0.000000 & -1.394768 & 0.000000 \\
$\mathrm{H}$ & -2.147997 & -1.240146 & 0.000000 \\
$\mathrm{H}$ & 2.147997 & -1.240146 & 0.000000 \\
$\mathrm{H}$ & 0.000000 & -2.480293 & 0.000000
\end{tabular}

Zero-point correction $=0.100106($ Hartree/Particle $)$

Thermal correction to energy $=0.104510$

Thermal correction to enthalpy $=0.105454$

Thermal correction to Gibbs free energy $=0.074986$

Sum of electronic and zero-point energies $=-232.200594$

Sum of electronic and thermal energies $=-232.196190$

Sum of electronic and thermal enthalpies $=-232.195246$

Sum of electronic and thermal free energies $=-232.225714$ 


\section{Thiophene}

$\begin{array}{cccc}\text { Symbol } & \mathrm{X} & \mathrm{Y} & \mathrm{Z} \\ \mathrm{S} & 0.000000 & 0.000000 & 1.198410 \\ \mathrm{C} & 0.000000 & 1.240900 & -0.011541 \\ \mathrm{C} & 0.000000 & -1.240900 & -0.011541 \\ \mathrm{C} & 0.000000 & 0.713953 & -1.271677 \\ \mathrm{H} & 0.000000 & 2.280330 & 0.281871 \\ \mathrm{C} & 0.000000 & -0.713953 & -1.271677 \\ \mathrm{H} & 0.000000 & -2.280330 & 0.281871 \\ \mathrm{H} & 0.000000 & 1.319413 & -2.169838 \\ \mathrm{H} & 0.000000 & -1.319413 & -2.169838\end{array}$

Zero-point correction $=0.066349($ Hartree/Particle $)$

Thermal correction to energy $=0.070440$

Thermal correction to enthalpy $=0.071385$

Thermal correction to Gibbs free energy $=0.039761$

Sum of electronic and zero-point energies $=-552.999173$

Sum of electronic and thermal energies $=-552.995081$

Sum of electronic and thermal enthalpies $=-552.994137$

Sum of electronic and thermal free energies $=-553.025760$ 


\section{Cyclobutadiene}

$\begin{array}{cccc}\text { Symbol } & \mathrm{X} & \mathrm{Y} & \mathrm{Z} \\ \mathrm{C} & 0.000000 & 0.666648 & 0.788667 \\ \mathrm{H} & 0.000000 & 1.433357 & 1.552845 \\ \mathrm{C} & 0.000000 & 0.666648 & -0.788667 \\ \mathrm{H} & 0.000000 & 1.433357 & -1.552845 \\ \mathrm{C} & 0.000000 & -0.666648 & -0.788667 \\ \mathrm{H} & 0.000000 & -1.433357 & -1.552845 \\ \mathrm{C} & 0.000000 & -0.666648 & 0.788667 \\ \mathrm{H} & 0.000000 & -1.433357 & 1.552845\end{array}$

Zero-point correction $=0.060751($ Hartree/Particle $)$

Thermal correction to energy $=0.064553$

Thermal correction to enthalpy=

0.065497

Thermal correction to Gibbs free energy $=0.036751$

Sum of electronic and zero-point energies $=-154.652071$

Sum of electronic and thermal energies $=-154.648269$

Sum of electronic and thermal enthalpies $=-154.647324$

Sum of electronic and thermal free energies $=-154.676071$ 


\section{1,3-Cyclohexadiene}

$\begin{array}{cccc}\text { Symbol } & \mathrm{X} & \mathrm{Y} & \mathrm{Z} \\ \mathrm{C} & 0.301350 & 0.706846 & -1.192614 \\ \mathrm{C} & -0.301350 & -0.706846 & -1.192614 \\ \mathrm{C} & 0.049047 & 1.423473 & 0.112636 \\ \mathrm{C} & -0.049047 & -1.423473 & 0.112636 \\ \mathrm{H} & -1.390053 & -0.644840 & -1.350138 \\ \mathrm{H} & 0.090907 & -1.282836 & -2.036065 \\ \mathrm{H} & 1.390053 & 0.644840 & -1.350138 \\ \mathrm{H} & -0.090907 & 1.282836 & -2.036065 \\ \mathrm{C} & -0.049047 & 0.731350 & 1.257463 \\ \mathrm{H} & 0.013385 & 2.509313 & 0.116054 \\ \mathrm{C} & 0.049047 & -0.731350 & 1.257463 \\ \mathrm{H} & -0.013385 & -2.509313 & 0.116054 \\ \mathrm{H} & -0.181992 & 1.245184 & 2.205244 \\ \mathrm{H} & 0.181992 & -1.245184 & 2.205244\end{array}$

Zero-point correction $=0.122020($ Hartree/Particle $)$

Thermal correction to energy $=0.127199$

Thermal correction to enthalpy $=0.128143$

Thermal correction to Gibbs free energy $=0.094442$

Sum of electronic and zero-point energies $=-233.349701$

Sum of electronic and thermal energies $=-233.344522$

Sum of electronic and thermal enthalpies $=-233.343578$

Sum of electronic and thermal free energies $=-233.377279$ 


\section{1,3-Butadiene}

$\begin{array}{cccc}\text { Symbol } & \mathrm{X} & \mathrm{Y} & \mathrm{Z} \\ \mathrm{C} & 0.600745 & 1.749720 & 0.000000 \\ \mathrm{H} & -0.324172 & 2.319755 & 0.000000 \\ \mathrm{H} & 1.522799 & 2.320235 & 0.000000 \\ \mathrm{C} & 0.600745 & 0.411319 & 0.000000 \\ \mathrm{H} & 1.551337 & -0.120412 & 0.000000 \\ \mathrm{C} & -0.600745 & -0.411319 & 0.000000 \\ \mathrm{H} & -1.551337 & 0.120412 & 0.000000 \\ \mathrm{C} & -0.600745 & -1.749720 & 0.000000 \\ \mathrm{H} & -1.522799 & -2.320235 & 0.000000 \\ \mathrm{H} & 0.324172 & -2.319755 & 0.000000\end{array}$

Zero-point correction $=0.084808($ Hartree/Particle $)$

Thermal correction to energy $=0.089464$

Thermal correction to enthalpy $=0.090408$

Thermal correction to Gibbs free energy $=0.059011$

Sum of electronic and zero-point energies $=-155.945472$

Sum of electronic and thermal energies $=-155.940816$

Sum of electronic and thermal enthalpies $=-155.939872$

Sum of electronic and thermal free energies $=-155.971269$ 


\section{Dimethyl sulfide}

$\begin{array}{cccc}\text { Symbol } & \mathrm{X} & \mathrm{Y} & \mathrm{Z} \\ \mathrm{C} & 0.000000 & 1.391325 & -0.515259 \\ \mathrm{H} & -0.892609 & 1.378937 & -1.143951 \\ \mathrm{H} & 0.892609 & 1.378937 & -1.143951 \\ \mathrm{H} & 0.000000 & 2.309790 & 0.072546 \\ \mathrm{C} & 0.000000 & -1.391325 & -0.515259 \\ \mathrm{H} & -0.892609 & -1.378937 & -1.143951 \\ \mathrm{H} & 0.000000 & -2.309790 & 0.072546 \\ \mathrm{H} & 0.892609 & -1.378937 & -1.143951 \\ \mathrm{~S} & 0.000000 & 0.000000 & 0.663363\end{array}$

Zero-point correction $=0.075760($ Hartree/Particle $)$

Thermal correction to energy $=0.080652$

Thermal correction to enthalpy $=0.081596$

Thermal correction to Gibbs free energy $=0.049361$

Sum of electronic and zero-point energies $=-477.982534$

Sum of electronic and thermal energies $=-477.977642$

Sum of electronic and thermal enthalpies $=-477.976698$

Sum of electronic and thermal free energies $=-478.008933$

\section{Methanethial}

$\begin{array}{cccc}\text { Symbol } & \mathrm{X} & \mathrm{Y} & \mathrm{Z} \\ \mathrm{C} & 0.000000 & 0.000000 & -1.028067 \\ \mathrm{H} & 0.000000 & 0.922595 & -1.609303 \\ \mathrm{H} & 0.000000 & -0.922595 & -1.609303 \\ \mathrm{~S} & 0.000000 & 0.000000 & 0.586688\end{array}$

Zero-point correction $=0.024722($ Hartree/Particle $)$

Thermal correction to energy $=0.027653$

Thermal correction to enthalpy $=0.028597$

Thermal correction to Gibbs free energy $=0.002401$

Sum of electronic and zero-point energies $=-437.474739$

Sum of electronic and thermal energies $=-437.471808$

Sum of electronic and thermal enthalpies $=-437.470864$

Sum of electronic and thermal free energies $=-437.497060$ 